\title{
A History of Dogs as Subjects in North American Experimental Psychological Research
}

\author{
Erica N. Feuerbacher \\ University of Florida \\ C. D. L. Wynne \\ University of Florida and Kyung Hee University
}

\begin{abstract}
The modern resurgence in psychological experiments involving dogs follows a long and rich tradition of using dogs as experimental subjects in psychology. Except for a few exceptions (e.g., Pavlov, and Scott and Fuller), much of this research is often overlooked. We trace the history of dogs as experimental psychological subjects: The work of Darwin and Pavlov sets the stage for our focus on research emanating from North American laboratories. We end our review with the advent of the modern renaissance of dog research. This account tracks the history of psychology as a science, providing insight into psychological processes and theoretical corollaries of these processes generally, and shedding light on the behavior of dogs specifically. A rediscovery of this literature can only aid research being conducted today, including rejuvenating old questions, suggesting new ones, and highlighting useful methods for current issues. We hope through this endeavor that those working with dogs will see themselves as part of this rich tradition and that a historical perspective will help integrate dog research into a field greater than the sum of its parts.
\end{abstract}

Keywords: history of psychology, dogs, Pavlovian conditioning, operant conditioning, animal cognition.

Dogs have much to recommend them as psychological subjects. They are as suitable for the study of basic behavioral processes as any typical laboratory animal but also have a number of unique attributes that encourage their study specifically. First, dogs are a highly social species. This allows for investigations into the mechanisms that produce and maintain conspecific social behavior, as well as the cognitive and behavioral by-products of those mechanisms. Dogs' high degree of sociality has led to them being studied

Erica N. Feuerbacher, Department of Psychology, University of Florida; Clive D. L. Wynne, Department of Psychology, University of Florida and Department of Biomedical Engineering, Kyung Hee University, Seoul, Korea.

We thank Donald Dewsbury for providing useful feedback on an earlier draft of this manuscript.

Correspondence concerning this article should be addressed to Erica Feuerbacher, Department of Psychology, University of Florida, P.O. Box 112250, Gainesville, Florida 32611. Email: efeuerbacher@ufl.edu, Phone: (940) 390 9830, Fax: (352) 3927985 . as an analog of human social behavior.

Moreover, some researchers have suggested that dogs' close evolutionary relationship with humans might have produced unique cognitive skills and behavioral repertoires in dogs (e.g., Hare \& Tomasello, 2005), including the ability to respond to complex cues from a heterospecific individual, and closer approximations to the abilities of humans than any other nonhuman species. The uniquely intimate relationship between dogs and humans offers researchers a unique social system unavailable in more traditional lab animals. Finally, the behavioral and morphological variability between breeds of dogs offers an unrivaled system for evaluating the interactions between phylogenetic and ontogenetic selection in the production of behavioral traits (e.g., Spady \& Ostrander, 2008). Thus, dogs offer researchers a rich spectrum of psychological research opportunities, some of which are found in few other species. Recognition of dogs' unique research prospects has been part of the impetus for 
the recent renaissance in comparative dog behavior and cognition (e.g., Kubinyi, Virányi, \& Miklósi, 2007).

The modern field of comparative dog cognition and behavior research can be dated to a handful of papers published in 1997 and 1998. Adam Miklósi and colleagues at the Eotvos Lorand University in Budapest, Hungary reported a correlation between dogs' problem solving abilities, their role in human lives (pet vs. working dog), and the owners' perceptions of their dogs (Topál, Miklósi, \& Csányi, 1997). In 1998, the same group demonstrated that pet dogs could locate a hidden food item by following a human pointing gesture (Miklósi, Polgárdi, Topál, \& Csányi, 1998). Independently, in the United States, Brian Hare and colleagues reported a very similar result (Hare \& Tomasello, 1998). The study of dog behavior and cognition has grown rapidly in the subsequent years. One measure of the growth of the field is that at the most recent annual international conference on comparative cognition (Melbourne, FL, 2010) over $10 \%$ of presentations concerned dogs and their relatives, whereas at the first such meeting in 1994, there was not a single paper on this subject group.

One thing that has arguably failed to develop during this period of increasing interest in dog behavior is an awareness of the century or more of research on dogs that preceded Miklósi's and Hare's groups' papers in 1997 and 1998. It is a common complaint that modern researchers are unaware of the history of their fields (Goodwin, 2004), but in the present case this phenomenon is particularly pronounced. The research that sprang up in the late 1990s had no direct connections to the previous scientific work. These earlier research traditions had largely died out by the 1980s and thus the modern field of dog cognition and behavior is particularly ahistorical.

Most classes in introductory psychology mention Pavlov and his dogs, and most classes on animal learning mention that the original studies that led to the development of the concept of "learned helplessness" were carried out on dogs in the 1950s (Solomon \& Wynne, 1953). Aside from these two contributions the only other widely-cited study on dogs is the classic monograph, Genetics and the Social Behavior of the Dog by John Paul Scott and John Fuller (1965). We show here, however, that dogs have been very popular subjects in studies on animal behavior and cognition dating back to Charles Darwin himself. The use of dogs as a subject species peaked in the 1960s, but declined over the rest of the twentieth century, before starting to increase in the first decade of the twenty-first century.

We have identified three broad categories of reasons for using dogs as psychological subjects: (a) they might be a convenient animal for the study of basic processes that are not unique to dogs; (b) they have useful, but not necessarily unique, behavioral or cognitive traits that can be used to study a more general phenomenon (e.g., the morphological and behavioral diversity between breeds can be studied to examine whether the factors that affect morphology have a concomitant effect on behavior); and (c) they have unique behavioral or cognitive traits that are themselves the focus of interest.

An interesting difference between much of the earlier work reviewed here and the current resurgence of research on dogs is a change in the reasons for using dogs as experimental subjects. Much current research using dogs as psychological subjects is directed at questions about dogs themselves, and most closely follows the third category of reasons for studying dogs listed above. Most of the earlier research was aimed at the first two categories of reasons for using dogs as subjects. The changing rationale for studying dog psychology might be part of the reason why older papers are seldom cited today.

Nevertheless, changing rationales for studying dogs do not detract from the earlier studies' potential to contribute to current and future research. Studies that used dogs to examine more ubiquitous psychological processes might become the foundation for contemporary comparative research to further tease apart the unique and nonunique behavioral and cognitive traits and mechanisms in dogs. Similarly, when dogs were used because of their behavioral resemblance to humans (their social behavior, in particular), the results have informed not only subsequent work on humans, but can also now shed light on current questions that are being pursued for the sake of learning about dogs themselves.

Sometimes earlier work in a field is of limited value as, for example, when technological advances render earlier studies irrelevant to modern researchers. In the area of animal behavior and cognition, however, technological advances, while important, have not had as great an impact as in many areas of science. Probably the only pieces of equipment commonly used today in the study of dog behavior and cognition that would not be familiar to researchers from the mid-twentieth century would be the video camera and computer touch screen (neither of which is essential to contribute to the peer-reviewed literature on dog psychology today). Of course, there have been advances in experimental design and statistical analysis, but absence of these features is hardly reason enough to ignore a study.

Of course, many earlier studies appear misguided to us today. In some cases their errors might be obvious and render a study uninformative. Other problems in a study might, however, involve issues that could not become apparent until the research was attempted. In this way, even flawed studies 


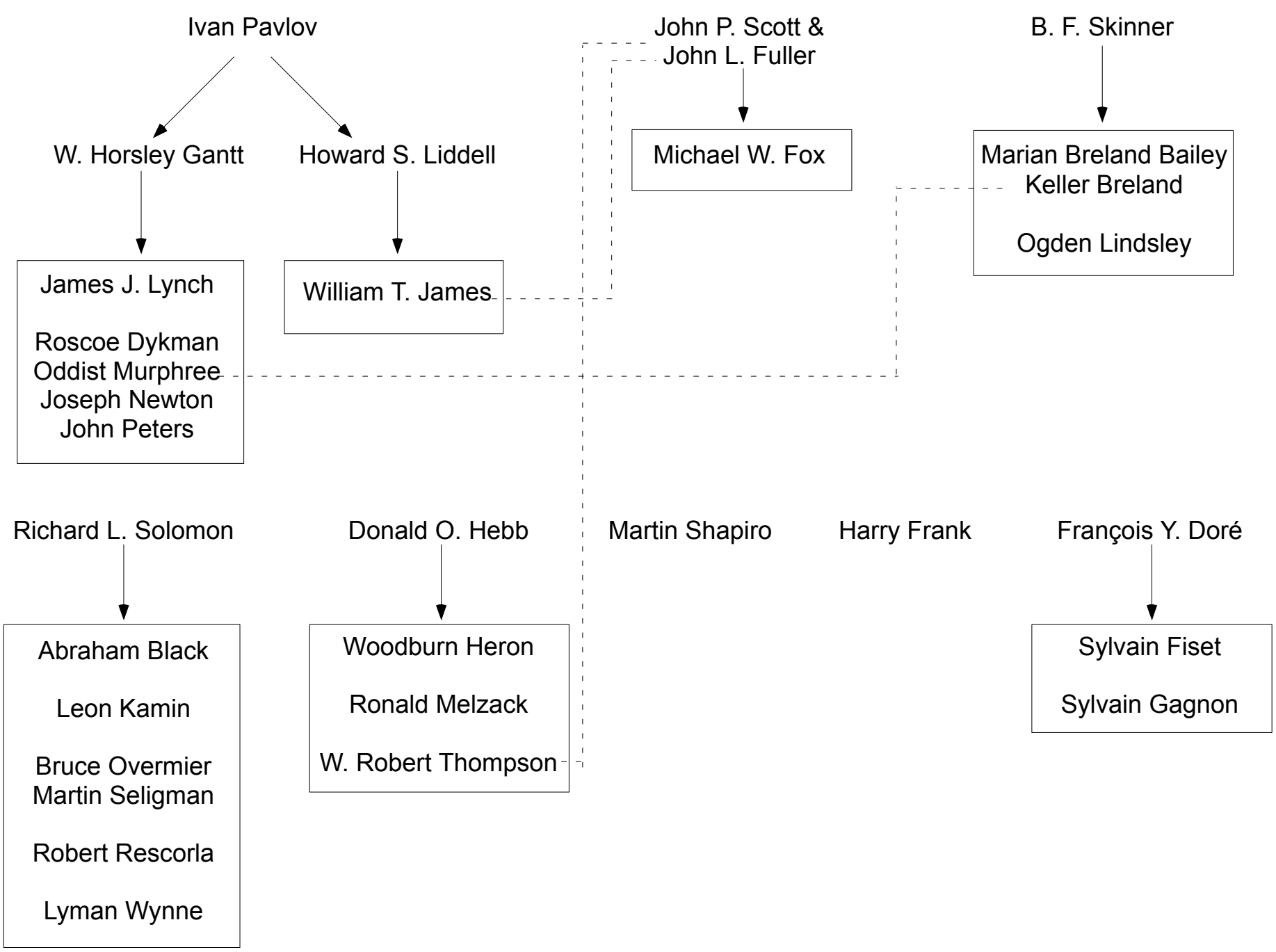

Figure 1. Flow chart showing the intellectual relationships between major researchers discussed in the text. Solid arrows (-) connect to boxes containing students, postdoctoral researchers, or laboratory associates of the primary investigator. Dashed lines (- - ) show direct scientific collaborations between researchers. For example, W. Robert Thompson from Hebb's lab worked with Scott and Fuller for a summer. The diagram does not show the more subtle influences that certainly exist between these researchers, such from papers or interactions at conferences. Boxes contain researchers who worked closely together (for example, the Arkansas researchers, Roscoe Dykman, Oddist Murphree, Joseph Newton, and John Peters).

can be of great use to contemporary researchers by showing them directions of research that, although possessing face validity, are unlikely to be productive.

Furthermore, much research carried out investigating the cognition and behavior of dogs prior to 1998 was by any measures competent or even excellent science. That contemporary researchers do not incorporate this work into their discussions is at least remiss and perhaps at times misleading.

In the current paper, we review the major lineages of research in experimental psychology on dogs emanating from North American laboratories (Figure 1). We start our review by contextualizing North American comparative psychology with Darwin and Pavlov, and end with the advent of the modern renaissance of research using dogs as experimental subjects in 1997. In defining our scope, we recognize the omission of much important work from outside North America; we have limited the paper in this way to prevent it from becoming unwieldy to the reader and possibly incomplete with regard to work that is unavailable in English, and therefore, largely inaccessible to the current authors. We hope that this paper will allow current researchers to reopen research on past questions with a new perspective, inform and improve current research through the addition of other relevant data, open new lines of research suggested from the older research with the benefit of historical perspective, and perhaps motivate others to delve into the research not covered in this paper. 


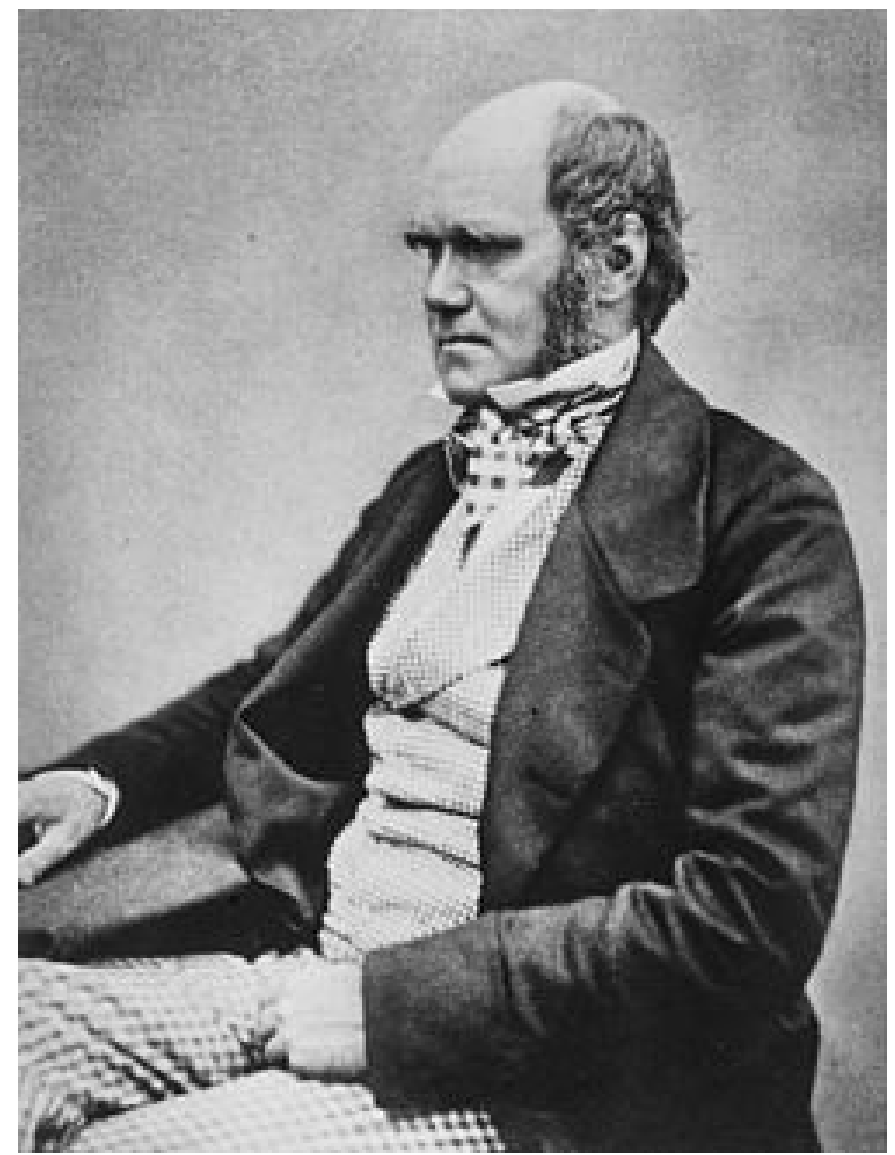

Figure 2. Charles Darwin. Father of evolutionary theory and early researcher in dog behavior and cognition. Image from Wikipedia in public domain.

\section{Darwin and His Advocates}

It is customary to date the beginnings of Comparative Psychology to the works of Charles Darwin (1809 - 1882). In the Origin of Species by Means of Natural Selection (1859) Darwin outlined how all species are related by descent to common ancestors. This provided an intellectual framework within which questions about the degree of psychological similarity between humans and other species became of central interest and inspired the first attempts to study the behavior of nonhumans (see Browne, 2003). Darwin theorized in more detail about the cognitive similarities between humans and other animals in the Descent of Man (1871). In chapters three and four, Darwin offered a "Comparison of the mental powers of man and the lower animals." At several points in that discussion Darwin referred to dogs, as when, for example, he suggested that the love of a dog for its master resembles the human belief in a god. Darwin listed the emotions seen in dogs; other psychological abilities such as imitation, memory, dreaming, and reason; moral qualities, the concept of property, and of self. Darwin's method in the Descent was based on his own informal observations and on reports offered to him by others. Darwin's behavioral observations would not be publishable in a modern scientific journal; nonetheless, his ideas have often proved correct.

The final work in which Darwin wrote extensively on animal psychology was The Expression of Emotions in Man and Animals (1872). Darwin's aim in this work was to demonstrate the universality of the expression of emotions across different species, including humans. In that volume, many of the illustrations of emotional expression are of a dog, specifically Darwin's own terrier (Townshend, 2009).

\section{George Romanes}

Darwin was not a professor and thus had no students in the formal sense. However, he inspired many contemporaries to study questions that grew out of his theory of evolution by natural selection. One of Darwin's intellectual advocates was George Romanes (1848-1894) (Wynne, 2007). Romanes' book, Animal Intelligence (1883), may be counted as the first post-Darwinian book-length treatment of its subject, and Romanes' affiliation with Darwin may be gauged from the fact that this book, published only months after Darwin's death, included a glowing eulogy to Darwin.

Chapter 16 of Romanes' Animal Intelligence was dedicated to dogs. Romanes added little to what Darwin had written a decade earlier in the Descent about dog psychological qualities. Romanes' anecdotes of dog "sagacity" were generally more credulous than Darwin's, but his approach to animal intelligence paralleled Darwin's. Romanes added an interesting nurturist note to Darwin's generally more nativist thinking on dog intelligence. Thus Romanes argued that the finer emotions ("Pride, sense of dignity, and self-respect" among others, p. 439) were only present in "well-treated" "high-life" dogs, and not in "Curs of low degree" (p. 439).

Although Romanes was mainly an anecdotalist, he was also the author of one of the first experimental studies of dog behavior. Romanes (1887) tested the ability of a setter-bitch, with which he had hunted for eight years prior to testing, to follow his scent under a range of circumstances. As a result of 16 tests in which he and his friends and servants walked around a large park wearing their own boots, each others' boots, or no boots at all, Romanes deduced that the dog identified his scent trail "by the peculiar smell of my boots..., and not by the peculiar smell of my feet" (p. 274). He further concluded that had he been "accustomed to shoot without boots or stockings, she would have learnt to associate with me a trail made by my bare feet" (p. 274) — though he did not carry out any experiments to test this hypothesis. 


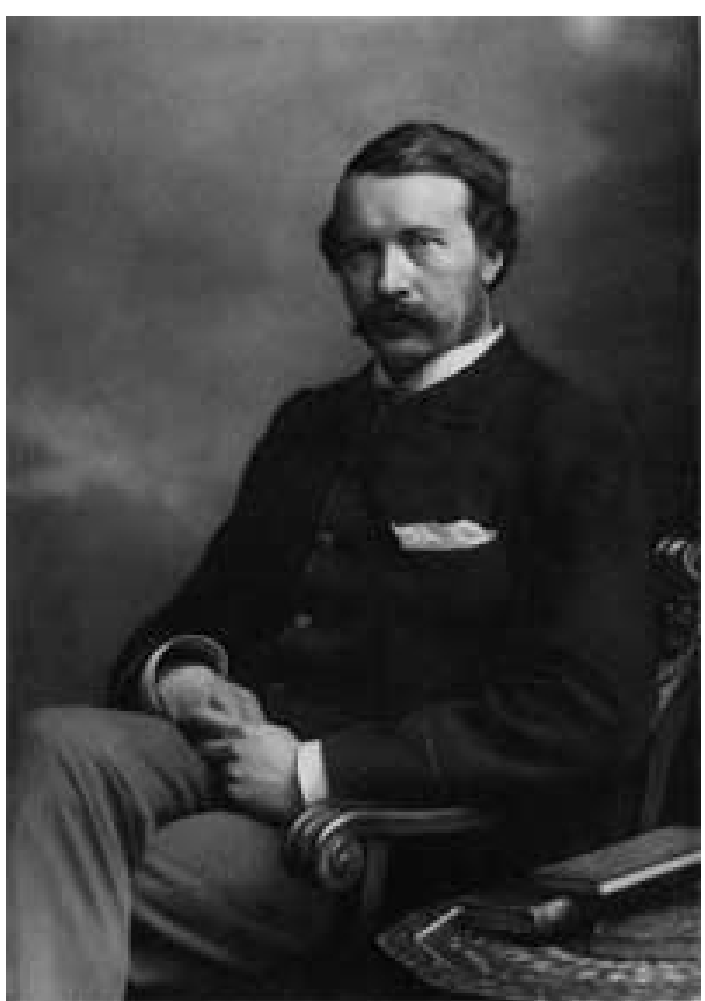

Figure 3. George Romanes, follower of Darwin who continued Darwin's interest in dog behavior and cognition. Image from Wikipedia in public domain.

\section{Sir John Lubbock}

A second individual directly influenced by Darwin to carry out an experiment on dog behavior was Darwin's neighbor at Downe, Kent, Sir John Lubbock (1834-1913). Lubbock (1884a, 1884b, 1889) gave his poodle, Van, the opportunity to convey its ideas to him by providing it with a set of pieces of stout cardboard, each with a word written legibly on it. The words used included "Food," "Bone," "Water," and "Out." Lubbock started by putting food in a saucer and placing the "Food" card over the top of it. Next to this, he placed an empty saucer with a blank card on top. Then Lubbock trained the dog to bring him the "Food" card before he gave the dog any food. In "about a month" (1884a, p. 276), the dog brought the food card in preference to the blank card (which did not lead to any food) on nine out of ten occasions. Lubbock also reported that the dog would bring him a card with "Out" on it when it wanted to go for a walk, and a card with "Water" written on it when it wanted to drink. It is not entirely clear how Lubbock knew that the dog was really requesting these outcomes. He commented: "No one who has seen him look along a row of cards and select the right one can, I think, doubt that in bringing a card he feels that he is making a request." (1884a, p. 548).

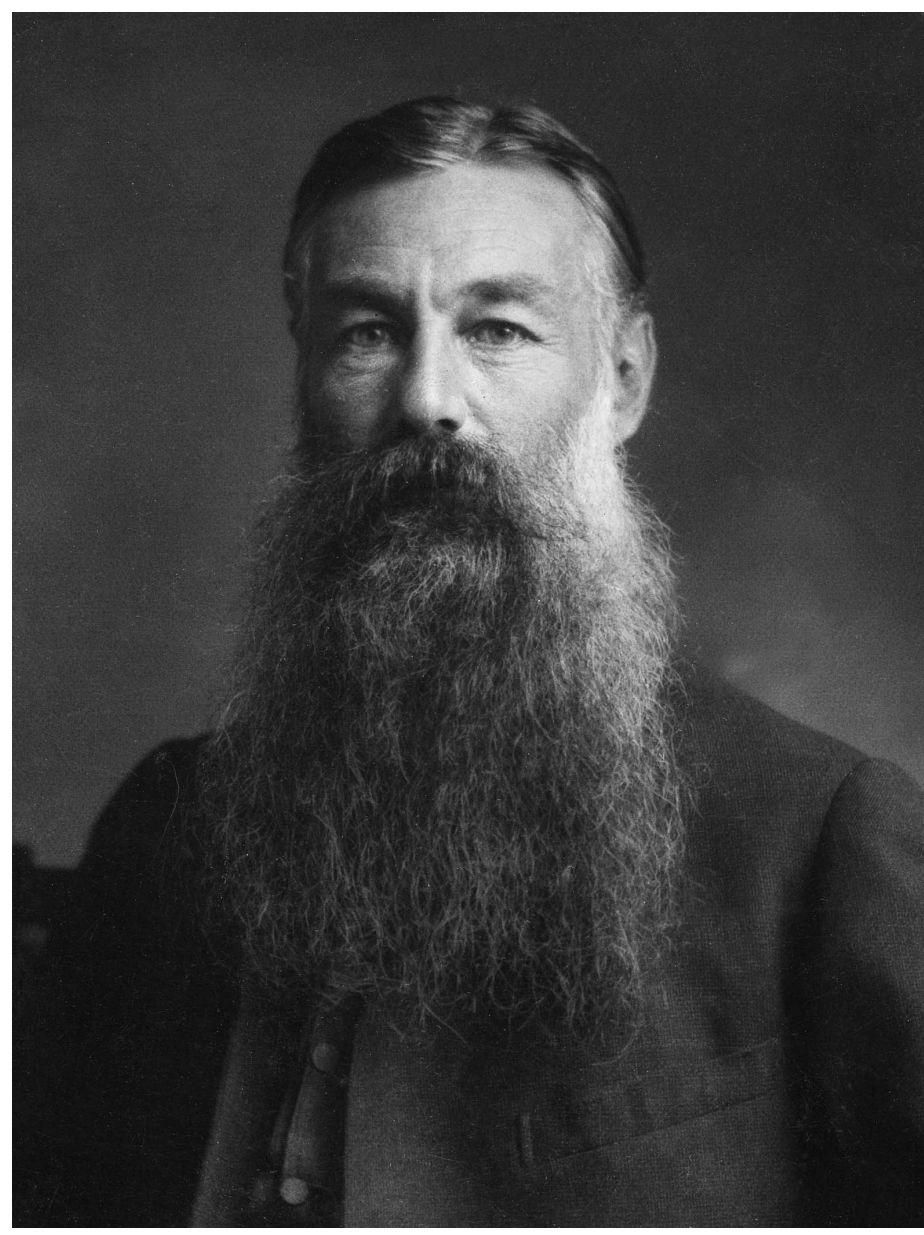

Figure 4. Conwy Lloyd Morgan, originator of Morgan's Canon and early researcher on dog behavior and cognition. Morgan took a more behavioral view of complex dog behavior. Image copyright the University of Bristol. Reproduced with permission.

\section{Conwy Lloyd Morgan}

The third early originator of the study of animal psychology to have been directly influenced by Darwin and who published some observations on dog behavior was Conwy Lloyd Morgan (1852-1936). Morgan spent most of his career at University College Bristol (today's University of Bristol) and is best known for his "canon" according to which the behavior of animals should not be ascribed to a "higher mental faculty" if it can be accounted for in terms of the "exercise of one which stands lower in the psychological scale" (1894, p. 53). Morgan's contribution to the discussion of dog intelligence consisted in what can be viewed as counterexamples to Romanes' anecdotes. Morgan described apparently ingenious behavior of dogs, which could nevertheless be accounted for through trial-and-error learning. The most commonly cited example is Morgan's dog, Tony, whose ability to open the latch to a garden gate might by a casual observer have been considered insightful. Morgan, however, recounted how careful observation over a period of time demonstrated that this behavior was in fact the 


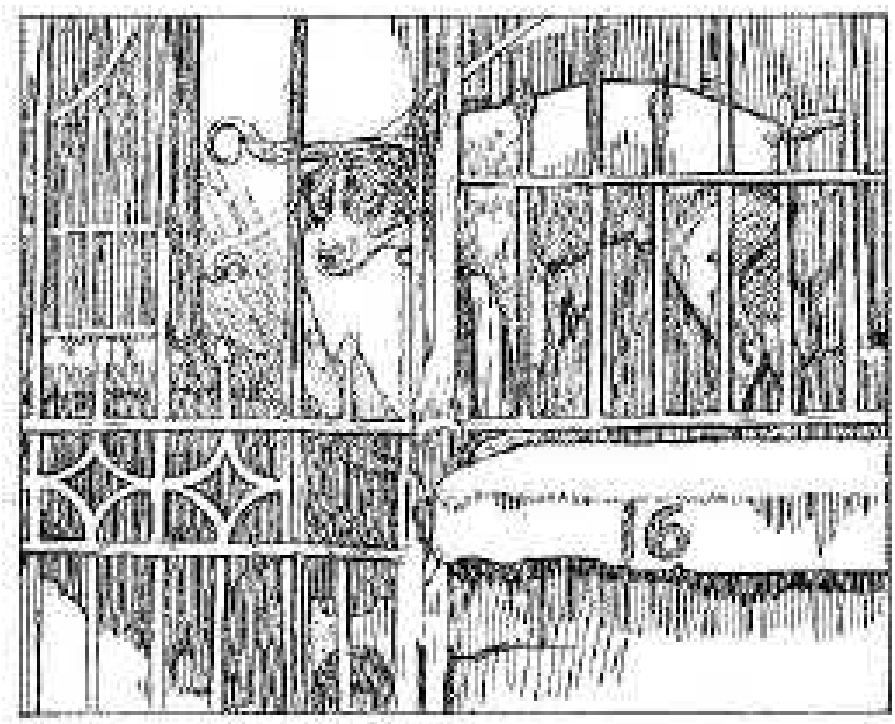

Figure 5. Lloyd Morgan's dog, Tony, lifting the garden gate latch with its head. Lloyd Morgan attributed the dog's behavior to gradual trial-and-error learning rather then insight. Reproduced from http://www.psy.tufts.edu/psych26/ morgan.htm with permission of Robert Cook.

outcome of an extended process of trial-and-error learning. Similarly, Morgan described how this same dog failed over repeated days of testing to ever turn a stick so that it would pass through the railings of a fence (Morgan, 1894).

\section{Pavlovian Conditioning Tradition}

\section{Pavlov and Bekhterev}

The British tradition inspired directly by Darwin failed to develop into an experimental science of dog behavior, but did set the stage for comparative lines of questioning in North America. To find the origins of the experimental study of dogs in psychology, we need to briefly discuss two Russian scientists whose work guided much of the experimental behavioral research on dogs in the early twentieth century and whose techniques are still used.

Ivan Pavlov (1849-1936) is the name most widely associated with psychological research in dogs, having elucidated conditioned reflexes using fistulated dogs to measure their salivary responses (thorough accounts of Pavlov's work can be found elsewhere: e.g., Todes, 2000, 2001). Although Pavlov's name is widely associated with these procedures, it is his rival, Vladimir Bekhterev (1857-1927), whose methods were most frequently used in North American experiments on conditioned reflexes.

Bekhterev focused on motor rather than glandular reflexes. He applied shock to elicit paw flexion and changes in respiration. The reasons for the adoption of Bekhterev's methods over Pavlov's are multifaceted, including issues of historical timing and some pragmatic preferences for his experimental techniques. Watson, in his 1915 American Psychological Association Presidential Address, mentioned Pavlov's techniques but focused on and expressed his preference for Bekhterev's (Ruiz, Sánchez, \& De la Casa, 2003; Watson, 1916), as did others (Brogden, 1962).

Pavlov's work nonetheless grew in influence in the United States in the 1920s through lectures by G. V. Anrep, a student of Pavlov's (Liddell, 1958), and Anrep's publication of a complete translation of a set of Pavlov's lectures (Pavlov, 1927). At the same time, the problem of gaining access to Bekhterev's Russian experimental papers, which were never translated into English, probably mitigated his continued influence.

Together, Pavlov's and Bekhterev's laboratories provided a wealth of research into the conditioned reflex in dogs and gave the world a powerful new methodology for objectively studying behavior. The conditioned reflex was these laboratories' primary research interest, not dog behavior, per se; however, the utility of their techniques and their results formed the basis for much of the experimental work involving dogs in North America, including some of our first understandings of the remarkable sensory capacities of dogs (Razran \& Warden, 1929).

\section{Pavlovians in America: W. Horsley Gantt and Students}

The entrée of Pavlov into America came through his students, in particular W. Horsley Gantt (1892-1980). (A second Pavlov student, Howard S. Liddell and his student, William T. James, are discussed in the Combining Traditions section below).

Gantt met Pavlov in 1922 and worked as a researcher in Pavlov's lab for nearly seven years before returning to Johns Hopkins University (Lynch, n.d.), where he founded the Pavlovian Laboratory in 1929. He later founded a second lab at the Veterans Administration Hospital in Perry Point, Maryland. In both labs, dogs were the primary experimental subjects. Though Gantt's initial choice of dogs was likely a result of working with Pavlov rather than an interest in dogs per se, as his research developed, Gantt focused on phenomena in dogs that are potentially relevant to many social species, including humans. As Gantt noted, "The dog has also a special advantage 1) stemming from his long and intimate association with the human being, and 2) because of his very responsive and easily influenced cardio-respiratory system" (Gantt, Newton, Royer, \& Stephens, 1966, p. 156).

Gantt identified five fields in which he made major contributions: (a) the relationship of the intensity of the stimulus to the magnitude of the response (Harvey, 1995); (b) 
psychopharmacology; (c) the role of the nervous system in conditioning; (d) cardiac conditioning; and (e) experimental neuroses (Reese, Peters, \& Dykman, 1987). Gantt typically utilized Bekhterev's motor reflex preparation, although he sometimes used the salivary reflex. He also attempted to condition other physiological systems, including the cardiac, respiratory, and renal systems (Ruiz et al., 2003). This multifaceted approach allowed for comparisons of the conditionability of different systems, which Gantt found were often differentially conditionable and not in accord. That is, the conditioned reflex, or CR, in one system might have extinguished, but the $\mathrm{CR}$ of another system to the same conditioned stimulus, or CS, continued, a status he termed schizokinesis (see Harvey, 1995; and Ruiz et al., 2003, for more complete descriptions of Gantt's conceptual framework). Gantt considered his work on cardiac conditioning the most interesting aspect of his research (Reese et al., 1987), and Harvey (1995) suggested that this work might have been his principal addition to Pavlov's studies.

The cardiovascular conditioning procedure also allowed Gantt to elucidate more clearly a phenomenon Pavlov had termed the social reflex (Lynch \& Gantt, 1968a, 1968b), and which Gantt called the effect of person (Lynch, 1987). This was the effect of one animal, whether conspecific or heterospecific, on another (Gantt, 1973). In this paradigm, Lynch and Gantt (1968b) used Pavlovian conditioning to measure the effect of humans on dogs' heart rates noting that, "the cardiovascular system may be a valuable index in studying the psychophysiology of [the] socialization process" (p. 69). They found that a dog's heart rate would spike (i.e., tachycardia) when a human walked in the room, but would decrease substantially (i.e., bradycardia) when the human petted the dog (Gantt et al., 1966).

Gantt et al. (1966) also noted that dogs' effect of person response often showed specificity to a particular person. The effects, both cardiac and motor, were larger and more variable to people with whom the dog had a "special relationship" (p. 152), compared to the dog's reactions to strangers. The exact history of the dog with the person who elicited those amplified responses was not described, such that the requisite contingencies to produce those effects remain to be explored.

Gantt's work also demonstrated various conditioning effects. For example, when a bell was a CS for petting, the bell elicited bradycardia (Gantt et al., 1966). However, the dogs' heart rate response to a tone associated with the entry of a passive human into the room did not show any conditioning effect (Newton, Teitelbaum, \& Gantt, 1968). The "effect of person" was also apparent when overlaid on other experimental contingencies. For example, when

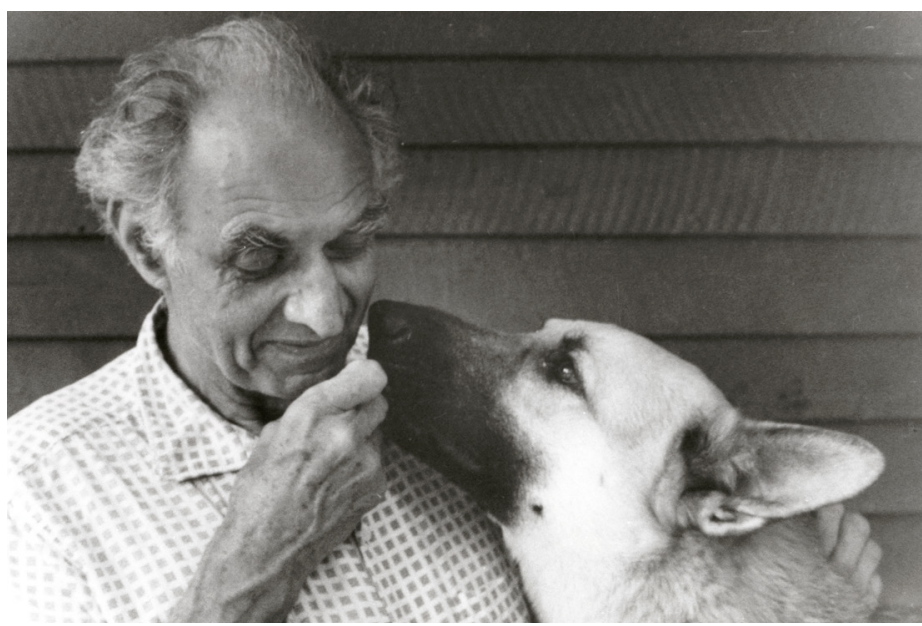

Figure 6. W. Horsley Gantt feeding dog, Gundy. Gantt was an American student of Pavlov and researched the "Effect of Person" in dogs. Image courtesy of the Alan Mason Chesney Medical Archives of the Johns Hopkins Medical Institutions.

unsignaled shocks were administered to dogs, the typical tachycardia elicited by the shock was considerably reduced when a human was petting the dog during the shock delivery (Anderson \& Gantt, 1966). James J. Lynch pursued more detailed analyses of the effect and found that the tachycardiac response to the CS and US were both reduced when a human petted the dog during the CS and US. The motor response (paw flexion) also diminished in the petting phase (Lynch \& McCarthy, 1967). This study pointed to the potential potency of tactile stimulation to reduce aversive conditioned responding.

In a follow up paper, Lynch and McCarthy (1969) investigated whether the effect of person elicited by a person entering the experimental room would vary if the dog had a differential history with the person. They found that heart rate increased the most when the human was associated with shock and increased the least when the human was associated with petting. These results further substantiated Gantt's view that petting might be a US for dogs. The effect of person was even more pronounced in two neurotic dogs (Gantt et al., 1966).

The effect of person is undoubtedly an interesting phenomenon and worthy of rediscovery, especially with the current interest in the intimate relationship enjoyed by dogs with humans. In their 1966 paper, Gantt et al. concluded that much more work on the effect of person was warranted. They suggested that there was a large amount of conditioning that went into producing the effect, as evidenced by its specificity to certain people. It remained unclear, however, whether there was also an underlying unconditioned stimulus property responsible for the behavioral relation, especially in the tactile component, and whether this property might be a product of phylogeny or early socialization. 
Gantt also ventured into the domain of personality; his interest in neuroses lent itself to research on individual differences. He investigated erratic heart rate and respiration, refusal to eat in the experimental chamber, loss of CRs to food, and variable sexual reflexes (Gantt, 1944). Gantt viewed putting a dog under experimental strain as a useful way to identify individual differences that might not have been apparent under normal circumstances. As Gantt (1944) noted, in this line of research he followed Pavlov, who had made mention of similar differentiation of types (e.g., inhibitory and excitatory) identified by subjecting the dogs to experimental strain and measuring the predominance of different conditioned responses.

Gantt advocated addressing individual differences by collecting many behavioral measures from different systems (e.g., motor, cardiovascular, and respiratory) and measuring their correlations. This suggestion presaged much of the work being done today in the field of dog temperament and personality (e.g., Sinn, Gosling, \& Hilliard, 2010; Svartberg $\&$ Forkman, 2002), in which statistical analyses are used to identify underlying behavioral structure that might influence a suite of behaviors. For those interested in this field, a rediscovery of Pavlov's work (e.g., Pavlov, 1927), as well as that of Gantt, and especially Gantt's theoretical deliberations (Gantt, 1944) on this topic, would be valuable.

Gantt had several other students and collaborators, who made unique and substantial contributions to our understanding of dog behavior. Roscoe Dykman, Oddist Murphree, Joseph Newton, and John Peters, among others, developed and studied what became known as the Arkansas nervous pointer dog line. Their work is discussed below in the Combining Traditions section.

Gantt clearly made substantial contributions to psychology in general, and to our understanding of dog learning and behavior in particular. He published over 700 articles (see Horvath, 1987, for a full list of Gantt's publications) and was nominated for a Nobel Prize in 1970 (Harvey, 1995). At the time that Gantt was working, neo-Behaviorism was at its peak and Gantt's work was largely overlooked (see Reese et al., 1987; and Ruiz et al., 2003 for discussion of possible contributing factors). Gantt's attention to experimental integrity in the tradition of Pavlov, and his use of singlesubject designs to give very complete analyses of individual differences and their persistence over an individual's lifetime, make his work worthy of rediscovery. It might shed light on contemporary issues as well as possibly reopen worthwhile research tracks that have been largely forgotten.

\section{The Operant Tradition: From Thorndike to Skinner, and Beyond}

While the Pavlovian tradition was emerging in Russia and finding its way to North America, another tradition was emerging in America: what would become known as operant conditioning.

Edward Thorndike (1874-1949) reported on puzzle box experiments with dogs in his 1898 book, Animal Intelligence, offering the first experimental work that could be classified as operant. More typically associated with his work on puzzle box learning with cats, Thorndike investigated dogs in similar boxes. Although Thorndike makes various references to dogs and their behavior in his book (1898), in his 1899 article, he focused mainly on the behavior of his cats; in one place noting only that, "the dogs presented no difference in behavior that would modify our conclusions" (p. 291). Much like the subsequent researchers discussed in this section, the choice of dogs as experimental subjects seems to have been one of convenience.

Following Thorndike's monograph, other experimental reports on dogs using operant methods emerged, but did not represent a cohesive body of research. One of the more prominent examples was W. T. Shepherd, a professor of psychology and philosophy at Waynesburg College, who published work comparing the "adaptive intelligence" of dogs, cats, and rhesus monkeys (1915) and the auditory discrimination ability of dogs (1919). Shepherd used experimental procedures much like those of Thorndike's.

Operant work on dogs did not begin to accelerate until the late 1940s and early 1950s. In the operant tradition, Clark Hull published one paper comparing the reinforcing effectiveness of regular feeding, sham feeding, in which the food did not reach the dog's stomach due to an esophageal fistula, and extinction (Hull, Livingston, Rouse, \& Barker, 1951). More work came from Skinner (1904-1990) and his students. The dog research of some of these students was one way in which Skinner exerted his influence.

\section{Skinner's Students: Marian Breland Bailey and Ogden Lindsley}

One of Skinner's first graduate students was Marian Breland (later Marian Breland Bailey, having remarried after Keller Breland's death) (1920-2001). While the Brelands, and later the Baileys, did not publish their experimental research on dogs in peer-reviewed journals, they did relate their experiences training animals in their book, Animal Behavior (Breland \& Breland, 1966). This work and their influence on the fields of comparative psychology and the world of animal training, and dog training in particular, warrant their 
mention. The Brelands started an animal training business in 1943 call Animal Behavior Enterprises (ABE) (see Bailey \& Bailey, 2006, for a more complete history). In their business, the Breland-Baileys were particularly interested in long-range control of behavior and worked on training field and utility dogs, including bomb-sniffing dogs. They constructed operant chambers for dogs, in which many response topographies could be measured and a variety of reinforcers delivered. Schedules of reinforcement were evaluated, largely to improve ABE's ability to maintain sustained performances in their dog performers (Bailey, personal communication, March 17, 2010). Their expertise in constructing operant chambers was put to use by other researchers in the field (e.g., Murphree, Dykman, \& Peters, 1967b).

The Breland-Baileys spearheaded the movement for humane training, which has particularly taken hold in the dog training world (e.g., Pryor, 1999); Bob Bailey stated their perspective: "Patience and preparedness are better then brute force" (Bailey \& Bailey, 2006).

Skinner had another graduate student, Ogden Lindsley (1922-2004), who elected to study dogs for his dissertation in large part because of their sociality, which he thought made them a better model species for human behavior (Lindsley, 2004). For this project, Lindsley built one of the earliest operant chambers for dogs (Lindsley, 1956). Lindsley investigated the effects of high doses of radiation on beagles' performance on discrimination tasks, calibrating the dogs' performance against their performance after being administered pharmacological agents such as alcohol, benzedrine, and nembutal (Lindsley, 2002). Lindsley (2002) reported that with the irradiation only food consumption was disrupted as the dogs sickened, but that the visual discrimination and the sound-conditioned fear suppression responses were sustained until the dog died. Several other lines of research using dogs as subjects followed the Skinnerian tradition, although the authors were not students of Skinner.

\section{Beyond Skinner: Roger W. McIntire}

One researcher working within an operant tradition but outside the direct influence of Skinner was Roger McIntire. McIntire made a unique contribution to research on dogs while working under contract for the United States Army. At the University of Maryland, McIntire started the Canine Behavior Lab, in which he investigated training techniques for fieldwork with Army dogs, a research program that sent an estimated 2500 working dogs to Vietnam (McIntire, personal communication, August 27, 2010). He published two defense reports from this work: one that focused on the utility of free-ranging dogs and dogs working within a

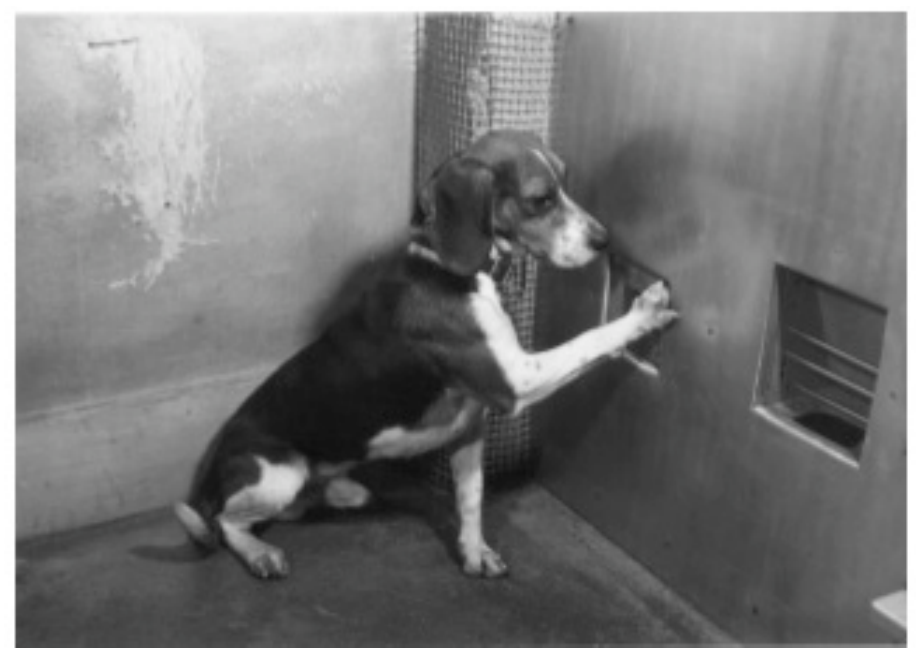

Figure 7. Hunter, one of Ogden Lindsley's research subjects, presses a panel in an operant chamber designed for dogs. Hunter survived an LD50 does of 300 roentgen units. The image is thought to be a personal picture from Lindsley's. Image originally published in the Journal of Experimental Analysis of Behavior, 77(3), p. 386. Image courtesy of the Society for the Experimental Analysis of Behavior, Inc., which holds the copyright.

foot patrol for personnel reconnaissance (McIntire, 1965), and another that investigated the role of early experience and selective breeding, and the utility of reinforcement (McIntire, 1967). Initially, the researchers used telemetered brain stimulation as a reinforcer for holding a pointing posture when a human scent was detected (McIntire, personal communication, August 27, 2010). However, this proved ineffective and McIntire soon switched to social reinforcement from the handler (e.g., McIntire \& Colley, 1967). From this work, he found no effects of the age at which training was initiated, nor large effects of selective breeding. He did, however, report that training was facilitated through finding the most powerful reinforcers and limiting the use of punishers (McIntire, 1968). McIntire also published an experimental paper investigating the effectiveness of human social reinforcement in training dogs and maintaining performance in working dogs (McIntire \& Colley, 1967). Together, these papers represent some of the few investigations into the role of human social interaction in maintaining responding in a dog. McIntire and Colley (1967) found that tactile reinforcement from the handler (petting) was effective in maintaining responding, whereas verbal praise alone was not. Although inconclusive, these results suggested that there might be primary and secondary reinforcing components to human interaction, a result that hearkens back to the effect of person reported by Gantt (e.g., Gantt et al., 1966). 


\section{Developmental Approaches}

\section{John Paul Scott and John L. Fuller}

In the 1950s, a new and highly influential research line was emerging that was "developmentally and socially oriented" (Scott, 1978). John Paul Scott (1909-2000) and John L. Fuller (1910-1992) began investigating the role of inheritance in dog behavior, helping to launch the field of behavioral genetics (Dewsbury, 2009). Their work was influenced by that of anatomist Charles Stockard, whose research will be briefly described below in the section "Combining Traditions."

As Scott and Fuller (1965) noted, the influence of heredity on behavior had been largely ignored during the rise of behaviorism in the 1930s and 1940s. A new program at Jackson Laboratory was designed to remedy this by assessing the hereditary influence on behavior in mammals.

The project that became known as "Genetics and the Social Behavior of Mammals" (Scott \& Fuller, 1965) had as its backdrop the fundamental goal of understanding human behavior; nonhuman, mammalian models were seen as convenient ways of addressing fundamental problems of human behavior. Dogs were chosen for the project in part because of Scott's perception that they exhibited greater sociality than more common lab species, which potentially could provide greater insights into human behavior (Dewsbury, 2009). The second reason for using dogs was the assumed range of genetic variability between the various dog breeds (Scott \& Fuller, 1965).

Because the work of Scott and Fuller and the history of Jackson Laboratory have been assembled in one tome, their 1965 masterpiece, Genetics and the Social Behavior of the Dog, as well as having been insightfully and thoroughly chronicled in other historical reports (Dewsbury, 2009, in press-a, in press-b), we will only give an overview of their immense project here. Scott and Fuller (1965) identified as one of their primary questions, "whether heredity could produce an important effect upon behavior in a higher animal or whether it simply set the stage for behavioral activity" (p. 3). The dog project spanned 23 years at Jackson Laboratory and involved the breeding, rearing, and study of over 300 dogs. Although the project started with more dog breeds, Scott and Fuller eventually narrowed the scope to focus on five dog breeds of similar morphology. This reduced the likelihood of physical characteristics producing any observed behavioral differences. They studied purebred dogs of all five breeds, as well as carefully crossed hybrids of two of the breeds (basenjis and cocker spaniels). The dogs were assessed on a battery of tests from birth until dogs were 1 year old.
Tests were broken into four classes: (a) performance tests, (b) emotional reactivity tests, (c) relationship tests, and (d) physical and physiological observations (Staff, 1950). We will focus on the first three. Performance tests were those tests in which the dogs had to complete a relatively simple task, but for which specialized training was often required before the assessment could be made. Such tests included: (a) leash control climbing tests, in which the dog's ability to learn to walk on a leash and navigate stairs was measured; (b) trailing tests, in which the dog was trained to locate an object; (c) barrier tests, in which the dog was placed in a novel environment and it had to figure out how to navigate to a hidden food bowl, with successive tests being more and more challenging; (d) discrimination tests, in which the dog had to make a correct choice in a T-maze based on a conditional discriminatory stimulus; (e) manipulation tests, in which the dog was presented with an inaccessible food bowl (the level of inaccessibility increased over trials) and had to learn to eventually manipulate a rope to access the food bowl; and (f) maze tests, in which the dog had to learn to navigate a complicated maze to access a food reward. The emotional reactivity tests were those in which the dog was subjected to mild but short-term stressors such as restraint, small cages, startling stimuli, pain (e.g., shock), threatening displays by the experimenter, or loud noises. Relationship tests investigated patterns of social behavior in the presence of conspecifics or humans. The tests with conspecifics included dominance tests, which involved presenting two dogs with a bone and measuring which dog had possession of the bone and for how long, as well as observations of social behavior including maternal and sexual behavior. Tests involving humans included handling tests, in which the dog's response to human approach and petting were recorded, and motivation tests, in which dogs were trained to follow the experimenter into the laboratory and the amount of time the dog was close to the experimenter during following was measured.

These tests did not seem to trace their origins to any specific research tradition, but Pavlov, Gantt and W. T. James, among others, influenced the program at Jackson Laboratory (Fuller, 1948). Scott and Fuller (1965) also cited Köhler as the source of their "umweg" barrier test. Köhler, in his book The Mentality of Apes (1925/1999), described the behavior of a single dog in a similar barrier test: the food was visually accessible, but the only way to physically access it was a circuitous route around the chain link fence separating dog and food. Finally, Scott and Fuller referenced Robert Tryon's work using mazes to identify individual differences in rats (Tryon, 1940).

Despite calling the compendium of their work Genetics and the Social Behavior of the Dog, which might seem to 
imply that the research found strong implications for the role of heredity in behavior, the work at Jackson Laboratory found only moderate to low heritabilities - an average of $27 \%$ (Dewsbury, in press-a) - for behavioral traits. As Dewsbury astutely pointed out, however, this result only indicated that in those specific test conditions, there was a large influence of the environment. Heritability values do not actually indicate the degree of genetic influence, or lack thereof, on the behavior of interest, nor are heritabilities able to be extrapolated to other studies. Scott and Fuller (1965) found breed differences on different tasks, but correlations were low, suggesting that there was not a unified single factor underlying the behavioral results (Dewsbury, in press-a). As Scott noted, "genetics does not put behavior in a straitjacket" (quoted in Dewsbury, in press-a, p. 21). As his work progressed, Scott changed positions from one that asserted a strong genetic influence, to one emphasizing the "plasticity and the flexibility of behavior" (Dewsbury, in press-a, p.24).

One concept that emerged from the Jackson Laboratory work that has attained widespread recognition is that of critical periods (e.g., Scott, 1958), an idea that Scott developed from embryology and for which he may be best known (Dewsbury, in press-a). The concept of critical periods suggests that there are certain juvenile phases during which the presence or absence of certain stimuli and experiences will have long-lasting effects in the adult, and any missed opportunities during the critical period are largely irremediable once that window of opportunity has closed. Based on the Jackson Laboratory work with puppy development, Scott and Marston (1950) identified four different stages in puppy development. Of the greatest practical implication was the socialization period, in which exposure to stimuli, especially social stimuli such as humans and conspecifics, was deemed essential if the puppy was to grow up to exhibit friendly social behavior to humans and conspecifics.

In 1968, the dog laboratory at Jackson Laboratory closed. John Paul Scott had departed three years earlier, taking a position at Bowling Green State University. At Bowling Green, he established a colony of dogs and continued to publish on dog behavior, especially focusing on the critical period hypothesis and the role of experience during critical periods in affecting attachment (e.g., Compton \& Scott, 1971; Gurski, Davis, \& Scott, 1980).

The influence of Scott and Fuller's work cannot be overstated for research that focuses on dog behavior, development, or genetics. It is unlikely that such a large endeavor, including the careful breeding and rearing of many dogs, will be undertaken again in the foreseeable future. Their 1965 treatise is an oft-cited data source, especially in the fields of development and behavioral genetics. Many researchers passed through the Jackson Dog Laboratory, particularly through the summer research program that Scott arranged. Thus, although the research conducted in this program often does not bear Scott or Fuller's name, a quick glance at the acknowledgements or grants that funded the work point to Jackson Laboratory at Bar Harbor. For example, Walter C. Stanley at the National Institute of Mental Health (NIMH) published four fascinating papers on humans and human interaction as reinforcers for normal and deprived dogs (Bacon \& Stanley, 1963, 1966; Stanley, 1966; Stanley, Morris, \& Trattner, 1965). The oeuvre emanating from Scott and Fuller's endeavor is much greater than indicated by a search for either of their names.

One collaborator who stands out as having made contributions to the psychological study of dogs beyond his time at Jackson Laboratory is Michael W. Fox. After working as a fellow at Jackson Laboratory, he published an impressive number and breadth of research articles on canids, balancing between psychology and ethology. His research included work on development of behavior in dogs, with attention to critical periods (e.g., Fox, 1964, 1969; Fox \& Stelzner, 1966a, 1966b), on neurological development and neurochemical substrates of behavior (Agrawal, Fox, \& Himwich, 1967; Fox, 1968), and on the behavior and ecology of urban dogs (Fox, Beck, \& Blackman, 1975). He also published many books, including Integrative Development in Brain and Behavior in the Dog (Fox, 1971) and The Wild Canids: Their Systematics, Behavioral Ecology and Evolution (Fox, 1975/2009).

Scott and Fuller's influence is also seen in other research lines, such as the work of D. O. Hebb and colleagues at McGill University, and the cognitive tradition that would follow. Before discussing those, we make passing mention of Jackson Laboratory's collaboration with Guide Dogs for the Blind of San Rafael, CA. Clarence Pfaffenberger, a member of the Board of Directors for Guide Dogs for the Blind, and Scott together published one scientific paper (Pfaffenberger \& Scott, 1959), as well as a volume entitled Guide Dogs for the Blind, Their Selection, Development, and Training (Pfaffenberger, Scott, Fuller, Ginsburg, \& Bielfelt, 1976). Pfaffenberger also went on to publish his own book, The New Knowledge of Dog Behavior (1963/2002), based on his work with Guide Dogs for the Blind. Based on Scott and Fuller's tests, Pfaffenberger developed puppy tests (Weiss \& Greenberg, 1997) to be used as selection tools for breeders, owners, and trainers. Similar tests in use today to assess adoptability of shelter dogs or utility of working dogs have their roots in Pfaffenberger's work. 


\section{Donald O. Hebb and Students}

A more direct line of influence from the Jackson Laboratory to other dog research comes through the work of Donald O. Hebb (1904-1985) at McGill University who attended a conference at Jackson Laboratory and started experiments on social isolation using Scottish terriers from Jackson Laboratory. As Scott pointed out (Scott, 1978), these experiments predated Harry Harlow's work with social isolation in primates. Later, a different lab would conduct a direct replication of Harlow and Zimmerman's classic study (1959) of wire vs. cloth surrogate mothers with dogs (Igel \& Calvin, 1960).

Hebb and his students and colleagues at McGill produced several studies investigating the effects of restricted early experience on later behavior. Puppies were reared to $71 / 2$ months of age in different states of deprivation. Conditions included being reared in a home environment, reared in the lab but with normal socialization, or reared in the lab but with no human contact except for routine cleaning and feeding. Within this last category, the puppies could be more or less sensory deprived, from living in a wire cage with visual access to their environment to living in a completely enclosed cage in which they could not see anything else. The behavioral effects of these early experiences were investigated using problem solving behavior (Clarke, Heron, Fetherstonhaugh, Forgays, \& Hebb, 1951; Thompson \& Heron, 1954b) and emotional responding (Melzack, 1954). The methods were reminiscent of Scott and Fuller's (1965) work and the research was largely longitudinal; tests were administered as the dogs matured, and after certain amounts of time had elapsed, since the isolated dogs had been placed in normal environments. The study confirmed the importance of early experience in later development, a view also championed by Scott and Fuller: Isolated dogs showed aberrant reactions to humans and novel environments (freezing), lower rates of conspecific social behavior, and poorer performance on the mazes. These differences persisted even after the experimental dogs had been moved to normal housing. Later studies expanded and generally supported these findings by augmenting the battery of tests to which the dogs were subjected (Thompson \& Heron, 1954b), and the variety of natural behaviors measured, such as exploration (Thompson \& Heron, 1954a), social behavior (Melzack \& Thompson, 1956), and aberrant behavior, such as "whirling," seen in the sensory restricted dogs (Thompson, Melzack, \& Scott, 1956).

During his time in Hebb's lab, Ronald Melzack expanded the investigation into social and sensory deprivation in dogs by investigating emotionality, fear, and pain in environmentally-restricted and normal dogs, as well as their ability to learn a shock-avoidance response (Melzack \&
Scott, 1957). Not all of the environmentally-restricted dogs responded to all of the noxious stimuli, and they were also largely incapable of learning an avoidance response, which the authors suggested represented an inability to respond adaptively as a result of their early experience. Additionally, the authors mentioned other abnormal behavior of the restricted dogs, including seemingly aimless movement such as banging into water pipes repeatedly.

To identify whether the behavioral differences in the isolated dogs were the result of physiological rather than psychological deficits, Melzack (1972) used a visual discrimination task to investigate differences in deprived and control dogs. The two groups performed differently on some tasks, which Melzack attributed to a difference in central nervous system arousal level, and not physiological deficits directly affecting the ability to discriminate (e.g., visual deficits). Deprived dogs were highly aroused which might have interfered with the discrimination performance. Finally, Melzack and Burns (1965) published a suggestive study in which electroencephalograms (EEG) and cortical responses supported the hypothesis that deprived dogs were unable to filter out irrelevant information in the same way as control dogs, paralleling later work on dog behavior from an information processing theory perspective (see subsection below on Harry Frank).

\section{Combining Traditions}

By the 1950s Pavlovian and Skinnerian research traditions were well established in North America, and the work of Scott and Fuller at Jackson Laboratory was under way. Thus, it is not surprising that research emerged investigating both conditioning procedures simultaneously, and often incorporating a developmental approach. In the work of these scientists, we find dogs playing a role in the development of psychology as a scientific field: Not only were dogs the subjects of several seminal papers on avoidance conditioning (e.g., Solomon, Kamin, \& Wynne, 1953; Solomon \& Wynne, 1953) and learned helplessness (Overmier \& Seligman, 1967), but the research done with dogs helped contribute to important theoretical developments of the time (e.g., Rescorla, 1966; Solomon \& Wynne, 1954). We first discuss William T. James, a student of the Pavlovian researcher, Howard S. Liddell, then turn to several students and collaborators of W. Horsley Gantt, before introducing new names in the field: Richard L. Solomon and his students, and Martin Shapiro.

\section{William T. James}

Whereas most early researchers working with dogs selected dogs for practical reasons, or because they had characteristics that were not unique to them, William $\mathrm{T}$. 
James (1903-1998) was more interested in dogs for their own sake (Liddell, 1938). His research attempted not only to answer questions of general psychological interest, but also questions specific to the understanding of dogs. Of the researchers discussed in this paper, it can readily be argued that James' research provided one of the most integrative programs, similar in scope to that of the Arkansas researchers, to be discussed in the following section. James' research spanned a considerable range of psychological domains, addressed entirely new questions in regard to dog behavior, transcended any particular methodological school, and continued for one of the longest periods of time (per Psycinfo, his first paper on dogs was published in 1933 and his last in 1971), creating one of the few cohesive research tracks working specifically on dogs.

James began working with dogs when he joined an enormous project of Charles Rupert Stockard (1879-1939), an anatomist interested in the endocrine effects on morphology and behavior (Shepard, 2001). Stockard ran a research "farm" located at Shrub Oak in New York which housed 500 mostly purebred dogs (James, 1988; Nonidez, 1941) and the products of carefully designed crosses. James conducted behavioral tests for Stockard using the conditioned reflex techniques he had learned from Liddell. From the research conducted at the Farm, Stockard wrote and edited an immense treatise, The Genetic and Endocrinic Basis for Differences in Form and Behavior (1941). One of the chapters detailed James' work at the Farm on conditioned salivary and avoidance (paw flexion due to shock) responses.

Stockard hypothesized that breed differences, even in behavior, were due to differences in the ductless glands. Scott and Fuller (1965) critiqued Stockard's work as promising for its time but ultimately misguided, given the inability of his experimental designs to test a Mendelian inheritance hypothesis. While working at the Farm, James began research on behavioral differences between various breeds of dogs, including basset hounds, beagles, English bulldogs, German shepherds, salukis, St. Bernards, and terriers, as well as carefully planned crosses of these breeds. Given his tutelage by Liddell, much of James' early work focused on differences between dogs in their response to Pavlovian conditioning procedures. Based on their reactions to salivary and motor conditioning experiments, James identified different typologies of dogs, similar to those developed by Pavlov (1927).

James identified German shepherds, salukis, and terriers as highly active (or "excited") breeds. Conditioned salivary reflexes in these dogs typically had a short delay between stimulus onset and response, but the response itself was not large in magnitude. Once a conditioned response was acquired, however, excited dogs readily generalized,

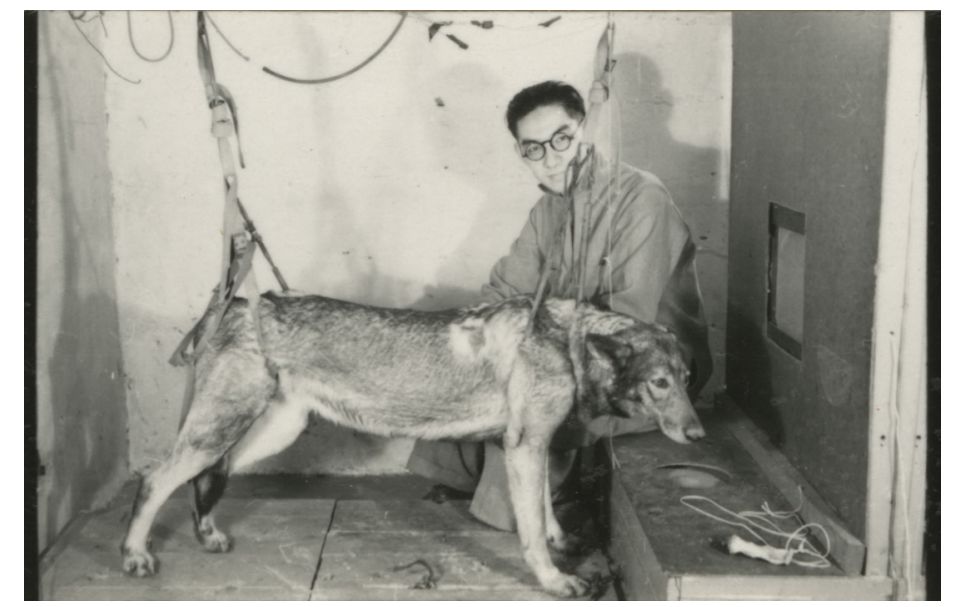

Figure 8. German shepherd in harness used by William T. James' in his work at the Cornell Dog Farm. James investigated breed differences in classical conditioning paradigms. The identity of the man with the dog is unknown. Courtesy of Hargrett Rare Book and Manuscript Library/University of Georgia Libraries.

often making discrimination training challenging. Their responses, especially to painful stimuli, were also slow to extinguish (James, 1941a, 1953b). One excited dog emitted 600 paw flexions to the CS after the shock contingency had been turned off and the response still had not extinguished (James, 1941a).

Basset hounds, beagles, and St. Bernards represented the other extreme: the highly inactive category. Inactive dogs readily formed conditioned salivary responses of large magnitude, but these soon decreased and were delayed from the onset of the CS. These dogs would often lean on the harness and would sometimes even fall asleep in the experimental chamber until the stimulus was introduced (James, 1953b).

Additionally, excited dogs flexed their paws with more force than did inhibited dogs (James, 1941a), and excited and inhibited dogs showed different patterns of activity in a 24-hour cycle, with excited dogs being more active (James, 1953b). James also reported that the only way he could modify an excited dog to an inhibited dog or vice versa was pharmacologically (James \& Ginsburg, 1949). A final difference he noted between the excited and inhibited dogs was their response to inescapable shock of increasing intensities (James, 1943). James raised the question of whether different types' had different thresholds for pain or tolerance of frustration.

James also crossed excited and inhibited dogs. The F1 generation fell as intermediates between the two extreme parental breeds on the conditioning experiments. The F2 generation, however, showed a greater range, with some dogs 
performing more like one of the extremes of the purebred grandparents, or as intermediates like the F1 generation (James, 1953b).

James' work on how different dog breeds and individuals respond to conditioning procedures has implications for research and practice in applied animal behavior, as well as suggesting useful ways for assessing behavioral differences for researchers interested in temperament and personality. Researchers interested in "trainability" might find the differences in generalization and resistance to extinction particularly useful. Additionally, his work investigating differences between breeds provides a significant parallel to the work we discuss in the following section by the Arkansas researchers who investigated differences between two strains of one dog breed.

Moving from a strictly Pavlovian approach, James incorporated operant research into his work after noting that "hyperexcitable" types of dogs were sometimes impossible to train to tolerate the harness and experimental apparatus (James, 1950). The utility of the operant approach, as James saw it, was that it allowed the animal freedom of movement, alleviating the stimuli that elicited resistance in the hyperexcitable dogs. James' enthusiasm for such an approach was apparent in his two publications on how to construct operant chambers for dogs (James, 1950, 1953a). He later published a paper on constructing an apparatus for studying the reinforcing effectiveness of sham vs. direct stomach feeding on operant responses and reported that only actual consummatory behavior, and not stomach injection of food, maintained lever pressing (James, 1963). He also investigated dogs' response patterns in an operant chamber (James, 1954) and found that the presence of the experimenter or another dog would evoke more responding than when the dog was alone, again pointing to interesting social relations that might affect dogs' performances in experiments.

James also investigated social interactions between puppies during feeding. He couched these studies in terms of dominance relations and social facilitation. Using a bowl from which only one puppy could eat at a time, and two mixed litters of beagles and terriers, James (1951) found that the terriers were always the dominant animals in this paradigm, even when they were smaller than beagles. He further explored dominance relations using a conditioned salivary procedure in which two dogs were tested simultaneously while standing next to each other. The relative status of the dog determined whether or not it would emit a conditioned salivary reflex (James, 1936).

James also found that food-satiated puppies would eat significantly more food when presented with the food again in the presence of littermates, compared to when the food

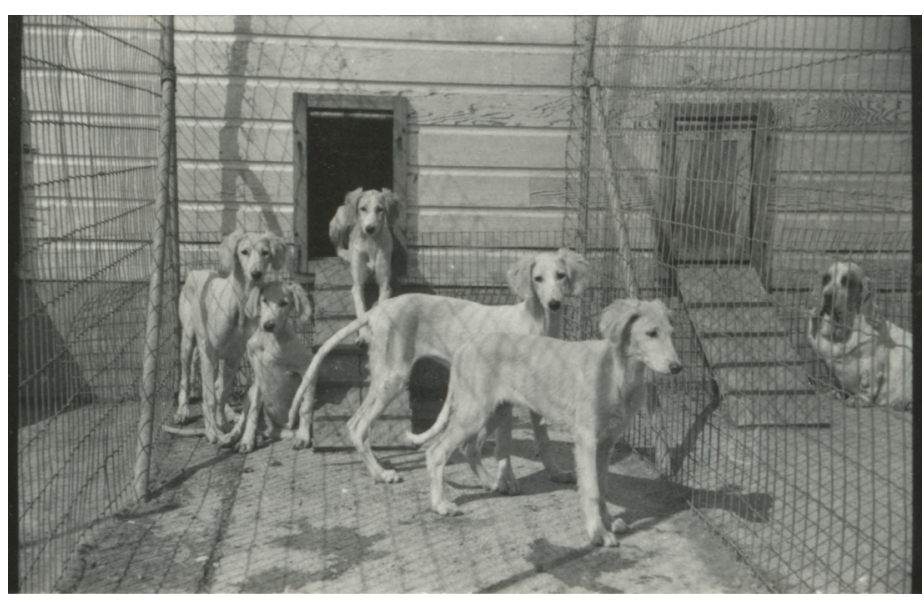

Figure 9. Saluki dogs and a Basset hound in their kennels at the Cornell Dog Farm, May, 1941. Anatomist Charles Stockard founded the Cornell Dog Farm and investigated morphological differences between breeds. William T. James investigated behavioral differences of these same dogs, largely using Pavlovian conditioning techniques. Courtesy of Hargrett Rare Book and Manuscript Library/University of Georgia Libraries.

was presented again in the absence of other puppies (James, 1953b). However, puppies that were reared alone after weaning did not show this social facilitation of feeding when first fed in a group (James \& Gilbert, 1955).

James conducted a separate study on social facilitation that did not involve feeding behavior and demonstrated a clever and fascinating research line worthy of more thorough follow-up (James, 1971). He trained one dog to avoid a US (spray of water) in the start box of a three-compartment runway maze and found that a naïve dog would learn the escape response simply through social facilitation. James could then extinguish the escape response also through social facilitation. The decoy dog did not run from the compartment and the target dog also stopped running, although this procedure did not fully tease apart extinction processes from social facilitation. This procedure warrants further investigation as a tool for studying social learning in dogs.

Finally, James also investigated the development of sensory systems and geotropic responses in puppies (James, 1952a, 1952b; 1956), and the effects of different levels of social deprivation on operant behavior in dogs for which the reinforcer was visual access to a conspecific (Angermeier \& James, 1961). Here his work overlapped with the work of Hebb and his students, as well as Scott and Fuller.

James' expansive work has given us a greater understanding of individual differences in dogs, as well as possible breed differences and techniques for further investigating these differences. On a theoretical level, he 
expanded Pavlov's view of individual nervous differences to differences that extend to the entire animal; for example, dogs deemed "excitable" through a conditioning procedure also had higher overall metabolic rates (James, 1941b). Although James often discussed individual differences with more of an essentialist slant than might be warranted, he clearly understood the interaction of the animal and the environment, and this interaction points to the utility of studying individual differences in both steady and transitional states during conditioning. This brief overview indicates the breadth of James' work and his substantial contribution to our understanding of dog behavior and learning.

\section{Pavlovians in Arkansas}

A unique research line emerged at the University of Arkansas in the 1960s and 1970s from a group of Pavlovians with various ties to Gantt (Reese, 1985; Reese et al., 1987). Together, Roscoe Dykman, Oddist Murphree, John Newton, and John Peters established and studied the Arkansas Line of Nervous Pointer Dogs (nervous dogs) and the normal counterpart line (normal dogs). The dogs were derived from two pairs of carefully selected working dogs - one pair of dogs that performed well in the field, and one pair of dogs that exhibited nervous behaviors, including freezing and cowering in the presence of humans. Such nervous pointers would occasionally crop up in a litter, but were usually culled by the breeder (Uhde, personal communication, August 6, 2010).

The two lines differentiated rapidly through inbreeding, with both strains breeding almost completely true (Dykman, Murphree, \& Peters, 1969). For over 18 years the group developed and investigated differences between the pointer lines in such a diverse array of approaches that this research program represents one of the most comprehensive and integrative research programs on dogs. Their research ranged from Pavlovian conditioning, operant conditioning, and behavioral tests from Scott and Fuller (1965) to crossbreeding the lines to assess possible genetic differences influencing the behavioral differences, and to using pharmacological and behavioral interventions to address the therapeutic potential for ameliorating anxiety disorders.

Much of the research from this group on the pointers followed Gantt's investigations into the effect of person, and provides an interesting extension of the different types of dogs investigated by Pavlov (1927) and William T. James (e.g., James, 1953b). In an unrestrained environment, both lines of pointer showed the typical decrease in heart rate to petting and a subsequent increase in heart rate when petting ended. However, when restrained, the bradycardia to petting occurred in the normal line but was absent in the nervous dogs (Thomas, Murphree, \& Newton, 1972). Whether these differences were driven entirely or in part by differences in amount of motor movement is unknown.

Performance on operant tasks was also evaluated in the two dog lines. In his 1974 paper, Murphree described in detail the procedures, apparatus, and special techniques for the nervous dogs. The lab enlisted Marian and Keller Breland to train their staff and construct an operant chamber with a treadle that could be pressed by the dogs, producing automated delivery of a piece of meat (Murphree, 1974; Murphree, Dykman \& Peters, 1967b). On this apparatus, many nervous dogs failed to perform at all, and those that did exhibited erratic, low rates of responding, whereas the normal dogs showed sustained responding with increasing rates over the first several sessions. The authors suggested that the failure of the nervous dogs was due to their "overwhelming anxiety or fear in any novel situation" (Murphree et al., 1967b, p. 416). This conclusion was supported by the improvement in bar-pressing acquisition when nervous dogs were administered chlordiazepoxide, a tranquilizer and anxiolytic drug (Angel, Murphree, \& DeLuca, 1974; Murphree, DeLuca, \& Angel, 1974). With a strong enough motivating operation in place (two to four days of water deprivation), however, nervous dogs did learn the response (Newton \& Chapin, 1978). Nevertheless, response rates of the nervous dogs were still lower than that of normal dogs, and correlated with independent measures of the degree of nervousness of each dog.

The research group also assessed the two lines of dogs on tests used by Scott and Fuller (1965). Nervous dogs showed less exploratory behavior in an empty room, had more subjects that froze in response to a loud horn, and a greater percentage of individuals avoided humans (Murphree, Dykman, \& Peters, 1967a). These differences appeared at 2 months of age and persisted through to the last test at 18 months of age. Some differences remained stable, and some became amplified with increasing age.

The Arkansas researchers also investigated the behavior of crosses between the two lines. They conducted reciprocal crosses and tested the crossbred puppies for the effect of person and on the behavioral tests taken from Scott and Fuller (1965). Between offspring of reciprocal crosses, there was no apparent difference. Both crosses behaved nearly identically to the nervous dogs when assessed for effect of person (Murphree, Peters, \& Dykman, 1967), as well as on the behavioral tests (Murphree \& Newton, 1971; Murphree, Peters, \& Dykman, 1969).

McBryde and Murphree (1974) undertook an investigation of whether it was possible to change a nervous pointer into a normal one - a question with both theoretical and practical importance. They noted that the nervous pointers still 
retained the normal behavior of "pointing" to the scent of quail. Using this kernel of normal behavior, the reinforcer of access to a quail wing, and sometimes a normal dog for social facilitation of responses, the authors trained five nervous pointers to hunt successfully, including retrieval, which necessarily involved approaching a human.

This behavioral improvement did not, however, generalize to the standard behavioral tests administered to the dogs. The authors broached a question relevant to all studies in which behavioral or temperament assessments are made: "How well do these behavioral tests represent the dog?" (McBryde \& Murphree, 1974, p. 83) and noted that the dogs appeared so normal when reviewing videos taken of their performances hunting that, "one easily gets the feeling that the rehabilitation has been very basic and that measures of animal behavior in an artificial setting may be inappropriate" (p. 83).

Work on the pointers continued when some of the dogs from the two strains were passed on to Thomas Uhde, then at the NIMH, who had become interested in the dogs as a potential model for human panic disorder (Uhde, personal communication, August 6, 2010). Research by Uhde and his collaborators focused on the physiological (e.g., Klein, Tomai, \& Uhde, 1990) and neurophysiological differences (e.g., Gurguis, Klein, Mefford, \& Uhde, 1990) that underlay the behavioral differences between the normal and nervous lines. The NIMH group also included further behavioral measurements (e.g., Klein \& Uhde, 1988), and discovered that many of the nervous dogs were deaf, but demonstrated that this deafness was not a factor in their behavioral differences from normal dogs (Klein, Steinberg, Weiss, Matthews, \& Uhde, 1987).

The Arkansas pointer lines formed a unique research paradigm that contributed richly to our understanding of the genetic and environmental bases of behavioral difference between dogs, including the development of potential therapies for shy or nervous dogs. The researchers involved presented a very integrative research program, systematically investigating the dogs' behavior using a variety of techniques. When combined with the work of William T. James, a fascinating picture of individual, strain, and breed differences begins to emerge, and both research programs have provided a multitude of ways to usefully investigate these differences. The pointer lines, unfortunately, were terminated by the 1990s (Uhde, personal communication, August 6, 2010).

\section{Richard L. Solomon and Students}

In the 1950s Richard L. Solomon initiated the study of avoidance behavior in dogs. At that time, avoidance behavior was an area of active controversy between behaviorist and cognitive researchers (Sidman, 1954; and see Herrnstein, 1969, for a history of the field). Solomon was a student of Harold Schlosberg who worked on white rats (e.g., Schlosberg, 1934). Why Solomon switched to dogs is unclear, but dogs were probably convenient subjects, and readily emitted observable escape responses that were well suited to shuttleboxes. Solomon's research using dogs would have a significant impact on the field of psychology (Rescorla, 1995). Solomon helped propose the two-process theory of conditioning (Rescorla \& Solomon, 1967), learned helplessness (Overmier, 1996), and the opponent-process theory of acquired motivation (LoLordo \& Seligman, 1997), all using results obtained from dogs.

Solomon published voraciously on avoidance conditioning in dogs. With Lyman Wynne, Solomon reported on avoidance conditioning in normal dogs and dogs whose autonomic nervous system had been surgically or pharmacologically disrupted (Solomon \& Wynne, 1955). In 1953, Solomon and colleagues published their first papers on avoidance conditioning on dogs using a shuttlebox preparation (Solomon et al., 1953; Solomon \& Wynne, 1953). A theoretical paper soon followed (Solomon \& Wynne, 1954) in which they expanded on the two-process theory of conditioning. In this theory, emotional fear responses result from Pavlovian conditioning and skeletal responses from operant conditioning, which are maintained through fear reduction.

One of the most well-known research paradigms to emerge from Solomon's lab was that of Bruce Overmier and Martin Seligman who coined the term "learned helplessness," (1967). In this work, Overmier and Seligman investigated the effects of prior shock history on a dog's behavior in later avoidance training. Dogs that had previously been administered unavoidable shocks showed three changes in behavior during the avoidance learning phase: "(1) many failures to initiate any escape response - that was interpreted as a 'motivational' deficit; (2) when an escape response did occur, the animal did not show any beneficial learning from the experience - that was interpreted as an 'associative' deficit; and (3) a marked quiet passivity in the presence of the continuing shocks that were not being escaped - that was interpreted as an 'emotional' deficit" (Overmier, 1996, p. 332). Steven Maier joined Seligman in identifying that the uncontrollability of the initial shocks was a critical feature for producing the later deficit in avoidance learning (Seligman \& Maier, 1967). Overmier (1996) indicated that this led the researchers to make an appeal for contingency analysis and a contingency-based learning theory in their theoretical paper on these phenomena (Maier, Seligman, \& Solomon, 1969). The learned helplessness research showed 
direct applicability to human behavior, serving as a potential model for clinical depression and post-traumatic stress disorder (e.g., Maier, 2001). This human connection was always an emphasis for Solomon (Overmier, 1996).

Abraham Black expanded the laboratory's interest in avoidance conditioning by investigating the extinction of avoidance responses in curarized dogs (Black, 1958). Avoidance-trained dogs that had experienced extinction while curarized required many fewer trials for the avoidance response to extinguish later when they were not curarized, as compared to dogs that had not been administered curare and could continue to make the avoidance response, even though the contingency had been removed. Black later pursued an impressive research program involving dogs in which he studied the interaction of conditioning, overt behavior, and brain activity. In this line, he experimentally demonstrated reinforcement of specific brain patterns using either avoidance learning (negative reinforcement) or brain stimulation (positive reinforcement) (Black, 1971). In 1970, Black, Young and Batenchuk reported that they successfully trained pharmacologically paralyzed dogs to emit an operant avoidance response of either more or fewer theta waves in their hippocampus. Furthermore, when the dogs were presented with the discriminative stimulus when they were not paralyzed, the effects of the prior learning manifested themselves in skeletal responses. Reversing the direction of the question, Black and Young (1972) additionally demonstrated that reinforcing overt behaviors could simultaneously select different brain wave patterns.

Robert Rescorla also earned his Ph.D. under Solomon investigating the effects of overlaying a Pavlovian fear conditioning procedure on a dog that was already responding on an unsignaled, or Sidman, avoidance schedule (Rescorla, 1967a). This work again investigated the interplay between operant and Pavlovian conditioned responses. He followed this with research aimed at dissecting the interaction of an operant Sidman avoidance schedule and a Pavlovianconditioned fear response (Rescorla, 1968), as well as the establishment of a positive reinforcer through contrast with shock (Rescorla, 1969). Rescorla's work on dogs also led to a seminal methodological paper in which he took issue with the then current control procedures used in Pavlovian conditioning (Rescorla 1967b). The papers Rescorla produced with dogs and the theorizing that came out of that work were of inestimable value.

Without doubt, the work on dogs in Richard Solomon's lab moved the field of psychology forward. Not only did Solomon's lab tackle important theoretical issues of the day, they produced performances in dogs that resulted in meaningful and powerful advances in our understanding of both dog and human behavior. Moreover, their thorough and methodologically precise work serves as a beacon for today's psychologists who use dogs as subjects.

\section{Martin M. Shapiro}

Whereas Solomon and colleagues' work used more of Bekhterev's preparation (shock) to produce conditioned responses, Martin M. Shapiro used Pavlov's salivary preparation when investigating the interaction of operant and Pavlovian conditioning (Shapiro, 1960a, 1960b). Shapiro used dogs' salivary response in an operant preparation in order to investigate the potential artificiality of the distinction between operant and Pavlovian conditioning (Shapiro, personal communication, August 12, 2010). Shapiro, Miller, and Bresnahan (1966) investigated the relationship between the discriminative and Pavlovian conditioned functions of a stimulus. Similarly, Shapiro, Mugg, and Ewald (1971) investigated the effect on operant behavior when a CS correlated more or less highly with the presentation of the US, which simultaneously served as the reinforcer for the operant response. Finally, Shapiro and Herendeen demonstrated the possibility of inhibiting a conditioned response by adding a response contingency to the CS-US delivery (Herendeen \& Shapiro, 1975; Shapiro \& Herendeen, 1975). In this experiment, dogs were only given food after presentation of a conditioned stimulus if they did not salivate during the 10 -second CS. This demonstration raises questions of the influence of operant conditioning procedures on responses typically thought of as mainly subject to Pavlovian conditioning control.

\section{Cognitive Tradition}

\section{Harry Frank}

The final tradition in psychology that we will follow here is the cognitive tradition into which much of the current work on dogs falls. Two research lines within this tradition are apparent: that of Harry Frank, and that emanating from a group of francophone Canadians. We will first consider Harry Frank's research, which he credits as having been an extension of Scott and Fuller's work (Frank, personal communication, July 29, 2010). Frank's research on dogs is intimately tied to an interest in dogs themselves and started on a personal note: After acquiring a malamute/elk hound cross in graduate school, and being erroneously informed that malamutes are at least $1 / 8$ wolf, he started noticing similarities to wolves in his dog's behavior. This turned itself into a research line when he later discovered that the Inuit tribe known for breeding the malamute was diligent about keeping wolf blood from entering their breeding lines. He was eventually persuaded to take a wolf pup to rear, and from those experiences was born a research program investigating the comparative development of wolves and 
dogs from a cognitive perspective.

Frank (1980) hypothesized that natural selection favored group hunting in wolves, so that they evolved a cognitive subsystem, including the capacity for foresight, mental representation, and the beginnings of an understanding of means-ends relations. Dogs, on the other hand, having been relieved of many of the selective pressures to which wolves are exposed, lost this cognitive complexity, and instead were selected for tractability in the domestication process (Frank \& Frank, 1987). From this hypothesis, Frank articulated a number of predictions testable by comparisons between wolves and dogs. He predicted "that dogs should perform better than wolves on learning tasks in which a) cues are arbitrarily selected by the experimenter, b) reinforcement is administered by the experimenter, and c) the to-be-learned behavior has no perceptible, functional connection with the outcome" (Frank \& Frank, 1987, p. 144). Wolves on the other hand should perform better on "problem solving tasks" that required "cognitive processes, such as foresight, planning, mental representation (imagery), and serial organization of behavior" (Frank \& Frank, 1987, p. 144).

The Franks conducted a longitudinal study comparing the behavior of socialized wolves and malamute dogs on a battery of performance tests starting when the pups were 6 weeks old and continuing until they were 25 weeks old. The training tasks represented a subset of those used by Scott and Fuller (1965) and were designated as either training or problem solving tasks.

While Frank and Frank generally found support for their initial hypothesis that dogs performed better on what the authors designated as training experiments and the wolves would perform better on those tasks designated as problem solving tasks, they also astutely noted several caveats in their 1987 summary of their work (Frank \& Frank, 1987), some of which apply as much to current work as to the studies at which they were originally directed. The first caveat was that attempts to equalize the early experience of the dogs and wolves were not wholly successful. For example, wolf pups were much more active during their first six weeks of life, which might have affected their behavioral repertoires in unknown ways and brought them into contact with contingencies not encountered by the dog pups. Thus, it is possible that the higher level differences (such as problem solving ability) found in older puppies are the products of earlier and possibly lower-level psychological differences and that the cognitive differences noted might be explained without necessitating appeals to evolutionary selection of higher psychical levels to explain those differences.

Second, this research involved only one breed of dog that has been artificially selected for specific traits and other

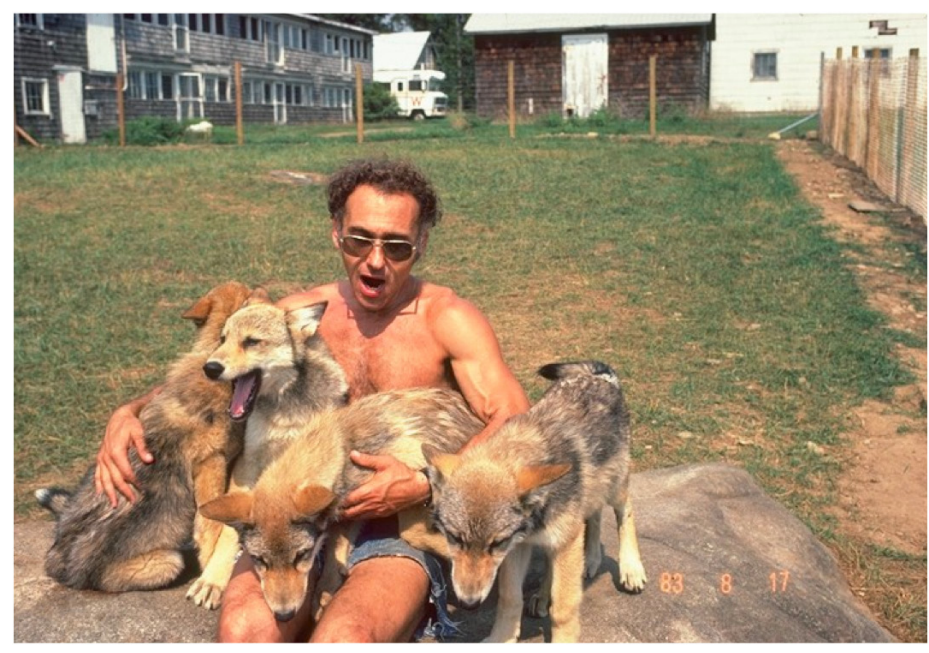

Figure 10. Harry Frank with wolf puppies from his research project in Connecticut. Frank investigated cognitive differences between wolves and Malamute dogs. Photo taken by Erich Klinghammer. Copyright Harry Frank. Used with permission.

breeds might perform differently. Indeed, Frank and Frank (1987) noted that Scott and Fuller's basenjis performed nearly as well and sometimes better than the wolves on problemsolving tasks, suggesting that there might not be wolf-dog differences on such tasks at all. Third, comparisons were only made until the pups were 25 weeks old, which might or might not be equivalent in dogs and wolves and the differences seen might be a result of differential rates of development and not indicative of differences that would be found in mature animals. Fourth, the differences seen could be explained by differences that do not impinge on information processing, such as sensitivity to the stress of confinement, or sensitivity to contingencies of reinforcement or punishment (Frank \& Frank, 1983), especially those administered by humans, rather than a difference in some cognitive capacity. We will add a final caveat, which is that the distinction between training and problem solving tasks is not well-defined and thus amenable to arbitrary manipulation: the authors noted that some tasks used could be interpreted as belonging to either the training task designation or the problem-solving designation (Frank, Frank, Hasselbach, \& Littleton, 1989), meaning that results would either confirm or disconfirm the hypothesis depending on how the task was viewed.

The authors were shrewd observers of their subjects' behaviors and noted small behavioral differences on tasks that might have contributed to observed differences in the overall task performance, such as the observation that wolf pups watched the food bowl and dog pups watched the manipulandum on the manipulation task (Frank \& Frank, 1987). For this reason alone, reading Frank and Frank's work is useful for guidance in identifying more discrete and well-defined behavioral differences between wolves and 
dogs that might be fruitfully investigated.

Frank and Frank placed their work in both information processing (Frank \& Frank, 1987) and Piagetian stage frameworks (Frank \& Frank, 1985). This tracked the departure of psychology in general from a behavioral to a cognitive approach. Although conditioning was addressed in this formulation, the emphasis was placed on the prepotent influence of genetic factors acquired through natural selection. The program eventually ended, but the influence of this research line can certainly be seen in much of the current research on canid cognition.

\section{François Y. Doré and Students}

The second strand of the early North American foray into canid cognition comes from a French lineage that found its way to Canadian universities. The major progenitor of the research and the students who currently continue this research is François Y. Doré. Doré published several papers outlining a neo-Piagetian approach to comparative cognition (Doré, 1991; Dumas \& Doré, 1989, 1991). It would be this Piagetian approach that Doré and his students, including Sylvain Gagnon and Sylvain Fiset, would take in investigating dog behavior. Gagnon demonstrated that dogs were successful on invisible displacement tasks, but not as successful as on visible displacement (Gagnon \& Doré, 1992). The dogs' success rate decreased as a function of the complexity of displacement and the delay between when the displacement occurred and when the dog was allowed to begin its search (Gagnon \& Doré, 1994). Finally, Gagnon and Doré (1994) reported a cross-sectional study to identify the age at which most dogs begin to solve invisible displacement problems, allowing for a preliminary understanding of the development of that complex behavior. Doré and his students have produced a cohesive oeuvre using Piaget's framework applied to animals and have demonstrated the potential fruitfulness of investigating complex behavioral repertoires in animals, and in dogs in particular.

\section{Conclusion}

The history of dogs as psychological subjects tells the tale of psychology as a science. We see the rise and fall of different theories and different areas of inquiry; we see the issues that were of greatest import or controversy in psychology at a given time; and we see the immensity of work on dogs that has often gone unnoticed. The research reviewed here was restricted to that emanating from North American laboratories, and there is surely an equivalent wealth of experimental research on dogs from other countries. For example, a search by the authors on the term "dog" using the Psycinfo database returned hundreds of papers in Russian. It is our hope that this paper will encourage others to delve into the great research resources not covered herein.

We have traced work using dogs as experimental psychological subjects in research originating from a Pavlovian tradition, and an operant tradition using dogs, to a developmental approach, through a cognitive approach, as well as research programs that have taken a clearly integrative approach combining several of these lines. Along the way, we have delved into research that clearly bears on current research interests, as well as introducing old discoveries worthy of more thorough examination, and suggesting new phenomena to explore.

Some of the research findings reviewed here concerned general issues, such as the investigation of avoidance conditioning by Richard Solomon and his students, or the effects of early deprivation from Donald Hebb and his students. Others investigated questions more particular to dogs, such as the relationship between humans and dogs in W. Horsley Gantt's effect of person, or the social relations between dogs examined by William T. James. Additionally, much of this research addressed behavioral and cognitive differences between individuals, strains, and breeds of dogs, and the development of these differences.

Despite the fact that much of the research reviewed here is between 40 and 70 years old, it has much to offer current researchers. The results of many studies still stand today, and others present well-documented phenomena, even as their theoretical explanations might have fallen away. Such studies would benefit from reinterpretation in today's understanding of behavioral and cognitive processes. For example, the work of Gantt and the effect of person might be usefully situated in our advancing understanding of Pavlovian conditioning effects, potentially even from the work of other researchers mentioned in this paper, such as Rescorla.

Furthermore, given the current and historical interest in the provenance of behavioral and cognitive differences between individuals, it is necessary to reassess some of the conclusions from the research we reviewed in light of our greater understanding of the interaction between genetics and the environment. For example, the Arkansas researchers concluded that the nervous behaviors in the pointer line were likely a result of simple Mendelian inheritance of a dominant trait. Given the benefit of further advances in our understanding of genetics, this conclusion seems overly simplistic. The nature-nurture dichotomy has been discarded, and the influence of both the environment and genetics on producing morphological, physiological, and behavioral traits is undeniable. In particular, the Arkansas researchers were working before two modern views of inheritance were available: (a) epigenetics, which has 
recently shown nongenetic inheritance of behavior passed on transgenerationally from both the maternal (e.g., Champagne \& Meaney, 2007) and even the paternal side (e.g., Alter, Gilani, Champagne, Curley, Turner, \& Hen, 2009) allowing for a more Lamarckian mode of inheritance; and (b) the concept of the "ontogenetic niche" (West \& King, 1987) in which inheritance is viewed as including not only genes, but environmental variables such as resources, and peers. In fact, their own study (McBryde \& Murphree, 1974) investigating therapeutic interventions for nervous dogs, pointed to the influence of the environment.

Finally, some of the phenomena we examined transcend in importance any particular tradition and bear on the study of dogs in general. For example, Gantt's research on the Pavlovian phenomenon of effect of person is relevant to all researchers working with dogs. While such an effect relates to research themes that seek to elucidate the doghuman relationship, it also serves as a cautionary note for experimenters when designing studies in which the dog is in contact with a human. Regardless of whether the research is addressing social issues between human and dogs, or asking entirely different questions, the presence of a human, the interaction with the human, and the dog's history with the human might differentially affect results. James' observation of similar effects of a human in an operant situation points to the generality of this concern.

In reviewing the considerable work from North America that has already been conducted in dogs, we hope that forgotten works have been dusted off that can inform current research, that forgotten questions might be reinvigorated and might find new life with new researchers, and that current researchers find themselves part of a larger, longer-lived, and vibrant tradition of using dogs as psychological subjects. Many of the reasons given by these earlier researchers for their choice of subject species are the same reasons current researchers cite in describing their choice of using dogs: their complex behavior, their sociality, and the breadth of morphological and behavioral differences.

This history has demonstrated the huge breadth of research in dogs, pulling from many traditions in psychology, all of which contribute to our understanding of dog behavior and cognition, regardless of the tradition in which we work individually. To this end, we turn to Paul Feyerabend and his circumspect view on the interaction of science and history: "It is clear that the increasing separation of the history, the philosophy of science and of science itself is a disadvantage and should be terminated in the interest of all these three disciplines. Otherwise we shall get tons of minute, precise, but utterly barren results" (Feyerabend, 2010, p. 28). None of the areas of psychological research focusing on dogs seems immune to the critique that, as a field, we are largely unaware of the substantial work that has gone before that of today. We have endeavored to bring to light the multifaceted, and often forgotten history of dogs as psychological subjects. In so doing, we hope that our field can understand its already well-established roots and synthesize the historical and modern work, and avoid the pitfalls foretold by Feyerabend of an ahistorical science.

\section{References}

Agrawal, H. C., Fox, M. W., \& Himwich, W. A. (1967). Neurochemical and behavioral effects of isolation-rearing in the dog. Life Sciences, 6(1), 71-78. doi:10.1016/00243205(67)90363-3

Alter, M. D., Gilani, A. I., Champagne, F. A., Curley, J. P., Turner, J. B., \& Hen, R. (2009). Paternal transmission of complex phenotypes in inbred mice. Biological Psychiatry, 66, 1061-1066. doi:10.1016/j.biopsych.2009.05.026

Anderson, S. L., \& Gantt, W. H. (1966). The effect of person on cardiac and motor responsivity to shock in dogs. Conditional Reflex, 1(3), 181-189.

Angel, C., Murphree, O. D., \& DeLuca, D. C. (1974). The effects of chlordiazepoxide, amphetamine, and cocaine on bar-press behavior in normal and genetically nervous dogs. Diseases of the Nervous System, 35(5), 220-223.

Angermeier, W. F., \& James, W. T. (1961). The influence of early sensory-social deprivation on the social operant in dogs. Journal of Genetic Psychology: Research and Theory on Human Development, 99, 153-158.

Bacon, W. E., \& Stanley, W. C. (1963). Effect of deprivation level in puppies on performance maintained by a passive person reinforcer. Journal of Comparative and Physiological Science, 56(4), 783-785.

Bacon, W. E., \&Stanley, W. C. (1966). Resistance to extinction after continuous and partial-reinforcement in basenji puppies. Psychonomic Science, 4(9), 327-328.

Bailey, R. E., \& Bailey, M. B. (2006). Patient Like the Chipmunks: The Story of Animal Behavior Enterprises (Long Version). Hot Springs, Arkansas: Animal Behavior Enterprises.

Black, A. H. (1958). The extinction of avoidance responses under curare. Journal of Comparative and Physiological Science, 51, 519-524.

Black, A. H. (1971). The direct control of neural processes by reward and punishment. American Scientist, 59, 236245.

Black, A. H., \& Carlson, N. J. (1959). Traumatic avoidance learning: A note on intertrial-interval responding. Journal of Comparative and Physiological Science, 52, 759-760.

Black, A. H., \& Young, G. A. (1972). Electrical activity of the hippocampus and cortex in dogs operantly trained to move and to hold still. Journal of Comparative and Physiological Science, 79, 128-141. 
Black, A. H. Young, G. A., \& Batenchuk, C. (1970). Avoidance training of hippocampal theta waves in flaxedilized dogs and its relation to skeletal movement. Journal of Comparative and Physiological Science, 70, 15-24.

Breland, K., \& Breland, M. (1966). Animal Behavior. New York, NY: Macmillan Company.

Browne, J. (2003). Charles Darwin: The power of place. Princeton, NJ: Princeton University Press.

Champagne,F. A., \& Meaney, M. J.(2007). Transgenerational effects of social environment on variations in maternal care and behavioral response to novelty. Behavioral Neuroscience, 121, 1353-1363. doi:10.1037/07357044.121.6.1353

Clarke, R. S., Heron, W., Fetherstonhaugh, M. L., Forgays, D. G., \& Hebb, D. O. (1951). Individual differences in dogs: Preliminary report on the effects of early experience. Canadian Journal of Psychology, 5(4), (150-156). doi:10.1037/h0083545

Compton, J. M., \& Scott, J. P. (1971). Allelomimetic behavior system: Distress vocalization and social facilitation of feeding in telomian dogs. Journal of Psychology: Interdisciplinary and Applied, 78(2), 165-179. doi:10.10 $\underline{80 / 00223980.1971 .9916900}$

Darwin, C. (1859). On the Origin of Species by Means of Natural Selection. London: John Murray.

Darwin, C. (1871). The Descent of Man; and Selection in Relation to Sex. London: John Murray.

Darwin, C. (1872). The expression of emotions in man and animals. London: John Murray. doi:10.1037/10001-000

Dewsbury, D. A. (2009). Origins of behavior genetics: The role of the Jackson Laboratory. Behavioral Genetics, 35(1), 1-5. doi:10.1007/s10519-008-9240-1

Dewsbury, D. A. (in press-a). John Paul Scott (1909-2000) and the study of genetics, development, and social behavior. In W. E. Pickren, D. A. Dewsbury, \& M. Wertheimer(Eds.), Portraits of Pioneers in Developmental Psychology. New York, NY: Taylor \& Francis.

Dewsbury, D. A. (in press-b). A history of the behavior program at the Jackson Laboratory: An overview. Journal of Comparative Psychology. doi:10.1037/a0021376

Doré, F. Y. (1991). A neo-Piagetian theory can contribute to comparative studies of cognitive development. Behavioral and Brain Sciences, 14(2), 368-370.

Dumas, C., \& Doré, F. (1989). Cognitive development in kittens (Felis catus): A cross-sectional study of object permanence. Journal of Comparative Psychology, 103(2), 191-200. doi: 10.1037/0735-7036.103.2.191

Dumas, C., \& Doré, F. (1991). Cognitive development in kittens (Felis catus): An observational study of object permanence and sensorimotor intelligence. Journal of Comparative Psychology, 105(4), 357-365. doi: $10.1037 / 0735-7036.105 .4 .357$
Dykman, R. A., Murphree, O. D., \& Peters, J. E. (1969). Like begets like: Behavioral tests, classical autonomic and motor conditioning, and operant conditioning in two strains of pointer dogs. Annals of the New York Academy of Sciences, 159, 976-1000. doi:10.1111/j.1749-6632.1969. tb12992.x

Feyerabend, P. (2010). Against Method (4th ed.). London, UK: Verso.

Fox, M. W. (1964). The ontogeny of behaviour and neurologic responses in the dog. Animal Behaviour, 12(23), 301-310. doi:10.1016/0003-3472(64)90016-8

Fox, M. W. (1968). Neuronal development and ontogeny of evoked potentials in auditory and visual cortex of the dog. Electroencephalography \& Clinical Neurophysiology, 24(3), 213-226. doi:10.1016/0013-4694(68)90002-3

Fox, M. W. (1969). Behavioral effects of rearing dogs with cats during the 'critical period of socialization.' Behaviour, 35(3-4), 273-280. doi:10.1163/156853969X00242

Fox, M. W. (1971). Integrative Development in Brain and Behavior in the Dog. Chicago, IL: University of Chicago Press.

Fox, M. W. (2009). Wild canids: Their systematics, behavioral ecology, and evolution. Wenatchee, WA: Dogwise Publishing. (Original work published 1975)

Fox, M. W., Beck, A. M., \& Blackman, E. (1975). Behavior and ecology of a small group of urban dogs (Canis familiaris). Applied Animal Ethology, 1(2), 119-137. doi:10.1016/0304-3762(75)90082-6

Fox, M. W., \& Stelzner, D. (1966a). Approach/withdrawal variables in the development of social behaviour in the dog. Animal Behaviour, 14(2-3), 362-266. doi:10.1016/ S0003-3472(66)80098-2

Fox, M. W., \& Stelzner, D. (1966b). Behavioural effects of differential early experience in the dog. Animal Behaviour, 14(2-3), 273-281. doi:10.1016/S0003-3472(66)80083-0

Frank, H. (1970). The interrelations among three personality systems. Dissertation Abstracts International, 30(10-A), 4547-4548.

Frank, H. (1980). Evolution of canine information processing under conditions of natural and artificial selection. Zeitschrift für Tierpsychologie, 53, 389-399.

Frank, H., \& Frank, M. (1983). Inhibition training in wolves and dogs. Behavioural Processes, 8, 363-377. doi:10.1016/0376-6357(83)90024-4

Frank, H., \& Frank, M. (1985). Comparative manipulationtest performance in ten-week-old wolves (Canis lupus) and Alaskan malamutes (Canis familiaris): A Piagetian interpretation. Journal of Comparative Psychology, 99, 266-274. doi:10.1037/0735-7036.99.3.266

Frank, H., \& Frank, M. (1987). The University of Michigan canine information-processing project (1979-1981). In H. Frank (Ed.), Man and Wolf: Advances, Issues, and Problems in Captive Wolf Research (pp. 143 - 167), 
Dordrecht, Netherlands: Dr W. Junk Publishers.

Frank, H., Frank, M., Hasselbach, M., \& Littleton, D. M. (1989). Motivation and insight in wolf (Canis lupus) and Alaskan malamute (Canis familiaris): Visual discrimination learning. Bulletin of the Psychonomic Society, 27, 455-458.

Frank, H., \&Tubbs, R. (1973). Relationship of rod-and-frame test performance to two dimensions of the personality assessment system. Perceptual and Motor Skills, 37, 747752.

Frank, Harvey, \& Verdun (2000). American responses to five categories of shame in Chinese culture: A preliminary cross-cultural construct validation. Personality and Individual Differences, 28, 887-896. doi:10.1016/S01918869(99)00147-6

Fuller, J. L. (1948). Individual differences in the reactivity of dogs. Journal of Comparative and Physiological Psychology, 41(5), 339-347. doi:10.1037/h0057680

Gagnon, S., \& Doré, F. (1992). Search behavior in various breeds of adult dogs (Canis familiaris): Object permanence and olfactory cues. Journal of Comparative Psychology, 106(1), 58-68. doi: $10.1037 / 0735-7036.106 .1 .58$

Gagnon, S., \& Doré, F. (1994). Cross-sectional study of object permanence in domestic puppies (Canis familiaris). Journal of Comparative Psychology, 108(3), 220-232. doi:10.1037/0735-7036.108.3.220

Gantt, W. H. (1944). Experimental Basis for Neurotic Behavior: Origin and Development of Artificially Produced Disturbances of Behavior in Dogs. New York, NY: Paul B. Hoeber. doi:10.1037/11517-000

Gantt, W. H. (1973). Reminiscences of Pavlov. Journal of Experimental Analysis of Behavior, 20, 131-136. doi:10.1901/jeab.1973.20-131

Gantt, W. H., Newton, J. E. O., Royer, F. L. \& Stephens, J. H. (1966). Effect of person. Conditional Reflex, 1(1), 146-160.

Gillaspy, J. A., Jr., \& Bihm, E. M. (2002). Marian Breland Bailey (1920-2001). American Psychologist, 57(4), 292293. doi:10.1037/0003-066X.57.4.292

Goodwin, C. J. (2004). A History of Modern Psychology (2nd ed.). Hoboken, NJ: Wiley and Sons, Inc.

Gurguis, G. N., Klein, E., Mefford, I. N., \& Uhde, T. W. (1990). Biogenic amines distribution in the brain of nervous and normal pointer dogs: A genetic animal model of anxiety. Neuropsychopharmacology, 3(4), 297-303.

Gurski, J. C., Davis, K. \&, Scott, J. P. (1980). Interaction of separation discomfort with contact comfort and discomfort in the dog. Developmental Psychobiology, 13(5), 463-467. doi:10.1002/dev.420130504

Hare, B., \& Tomasello, M. (1998). Communication of food location between humans and dogs (Canis familiaris). Evolution of Communication, 2, 137-159. doi:10.1075/ eoc.2.1.06har
Hare, B., \& Tomasello, M. (2005). Human-like social skills in dogs? Trends in Cognitive Sciences, 9, 439-444. doi:10.1016/j.tics.2005.07.003

Harlow, H. \& Zimmerman, R. S. (1959). Affectional responses in the infant monkey. Science, 130, 421-432. doi:10.1126/science.130.3373.421

Harvey, A. M. (1995). W. Horsley Gantt--A legend in his time. Integrative Physiological and Behavioral Science, 30, 237-243. doi:10.1007/BF02698578

Herendeen, D. L., \& Shapiro, M. M. (1975). Extinction and food-reinforced inhibition of conditioned salivation in dogs. Animal Learning and Behavior, 3(2), 103-106. doi:10.3758/BF03209109

Herrnstein, R. J. (1969). Method and theory in the study of avoidance. Psychological Review, 76(1), 49-69. doi: $10.1037 / \mathrm{h} 0026786$

Horvath, M. (Ed.) (1987). Publications of W. Horsley Gantt. Integrative Physiological and Behavioral Science, 22, $52-$ 74. DOI: $10.1007 / \mathrm{BF} 02700417$

Hull, C. L., Livingston, J. R., Rouse, R. O., \& Barker, A. N. (1951). True, sham, and esophageal feeding as reinforcements. Journal of Comparative and Physiological Psychology, 44(3), 236-245. doi:10.1037/h0063258

Igel, G. J., \& Calvin, A. D. (1960). The development of affectional responses in infant dogs. Journal of Comparative and Physiological Psychology, 53(3), 302205. doi:10.1037/h0049308

James, W. T. (1936). The effect of the presence of a second individual on the conditioned salivary response in dogs of different constitutional types. Pedagological Seminary and Journal of Genetic Psychology, 49, 437-449.

James, W. T. (1941a). Experimental observations indicating the significance of work on conditioned motor reactions. Journal of Comparative Psychology, 32(2), 353-366. doi: $10.1037 / \mathrm{h} 0058101$

James, W. T. (1941b). Morphological form and its relation to behavior. In The Genetic and Endocrinic Basis for Differences in Form and Behavior (525-643). C. R. Stockard (ed.). Philadelphia, PA: Wistar Institute of Anatomy and Biology.

James, W. T. (1943). The formation of neurosis in dogs by increasing the energy requirement of a conditioned avoiding response. Journal of Comparative Psychology, 36(2), 109-124. doi:10.1037/h0054870

James, W. T. (1950). Operant conditioning apparatus for dogs. Journal of General Psychology, 43, 143-145. doi: 10 $.1080 / 00221309.1950 .9710612$

James, W. T. (1951). Social organization among dogs of different temperaments, terriers and beagles, reared together. Journal of Comparative and Physiological Psychology, 44(1), 71-77. doi:10.1037/h0061218

James, W. T. (1952a). Observations on behavior of new-born puppies: Methods of measurement and types of behavior 
involved. Pedagological Seminary and Journal of Genetic Psychology, 80, 65-73.

James, W. T. (1952b). Observations on behavior of new-born puppies: II. Summary of movements involved in group orientation. Journal of Comparative and Physiological Psychology, 45(4), 329-335. doi:10.1037/h0062288

James, W. T. (1953a). An improved operant conditioning apparatus for dogs. Journal of General Psychology, 48, 75-77. doi:10.1080/00221309.1953.9920176

James, W. T. (1953b). Morphological and constitutional factors in conditioning. Annals of New York Academy of Sciences, 56, 171-183. doi:10.1111/j.1749-6632.1953. tb30215.x

James, W. T. (1956). The geotropic reaction of newborn puppies. Journal of Genetic Psychology: Research and Theory on Human Development, 89, 127-130.

James, W. T. (1963). An analysis of esophageal feeding as a form of operant reinforcement in the dog. Psychological Reports, 12, 31-39.

James, W. T. (1971). A methodological study of conditioning and extinction of an avoidance response via social facilitation in dogs. Journal of General Psychology, 84(2), 275-279. doi: 10.1080/00221309.1971.9711313

James, W. T. (1988). Autobiography of William T. James. William T. James Papers (1927-1998) (Box 17), Hargrett Library (UGA 04-024/ UGA 05-036), Athens, GA. Courtesy of Hargrett Rare Book and Manuscript Library/ University of Georgia Libraries.

James, W. T., \& Gilbert, T. F. (1955). The effect of social facilitation on food intake of puppies fed separately and together for the first 90 days of live. British Journal of Animal Behaviour, 111, 131-133. doi:10.1016/S09505601(55)80050-0

James, W. T., \& Ginsburg, B. E. (1949). The effect of prostigmine on the conditioned response of inhibited dogs.' Journal of Comparative and Physiological Psychology, 42(1), 6-11. doi:10.1037/h0061847

Klein, E., Steinberg, S. A., Weiss, S. R. B., Matthews, D. M., \& Uhde, T. W. (1987). The relationship between genetic deafness and fear-related behaviors in nervous pointer dogs. Physiology \& Behavior, 43(3), 307-312. doi:10.1016/0031-9384(88)90192-8

Klein, E. H., Tomai, T., \& Uhde, T. W. (1990). Hypothalamopituitary-adrenal axis activity in nervous and normal pointer dogs. Biological Psychiatry, 27(7), 791-794. doi:10.1016/0006-3223(90)90595-S

Klein, E., \& Uhde, T. W. (1988). 24-hour motor activity in genetically nervous and normal pointer dogs. Biological Psychiatry, 23(5), 523-527. doi:10.1016/00063223(88)90026-1

Köhler, W. (1999). The Mentality of Apes. E. Winter (Trans.). Retrieved from http://books.google.com/books (Original work published 1925)
Kubinyi, E., Virányi, Z., \& Miklósi, Á. (2007). Comparative social cognition: From wolf and dog to humans. Comparative Cognition \& Behavior Reviews, 2(1), 26-46. doi: $10.3819 /$ ccbr.2008.20002

Liddell, H. S. (1938, March 24). [Letter to W. T. James]. Howard S. Liddell Papers, \#14-23-1466 (Box 2, Folder 8), Division of Rare and Manuscript Collections, Cornell University Library.

Liddell, H. S. (1958). History and prospects of the behavior farm laboratory at Cornell University. In H. Gantt (Ed.) The Physiological Basis of Psychiatry. Springfield, IL: Chas $\mathrm{C}$ Thomas.

Lindsley, O. R. (1956). Conditioned suppression of behavior in the dog and some sodium pentobarbital effects. (Unpublished doctoral dissertation). Harvard University, Cambridge, MA.

Lindsley, O. R. (2002). Our Harvard pigeon, rat, dog, and human lab. Journal of Experimental Analysis of Behavior, 77(3), 385-387. doi:10.1901/jeab.2002.77-385

Lindsley, O. R. (2004, May 28). Interview with Ogden Lindsley. Interviewed by Alexandra Rutherford. Copy in possession of first author.

LoLordo, V. M., \& Seligman, M. E. P. (1997). Richard Lester Solomon (1918-1995). American Psychologist, 52(5), 567-568. doi:10.1037/0003-066X.52.5.567

Lubbock, J. (1884a). Teaching Animals to Converse. Nature, 29(740), 216. doi:10.1038/029216a0

Lubbock, J. (1884b). Teaching Animals to Converse. Nature, 29(754), 547-548. doi:10.1038/029547c0

Lubbock, S. J. (1889). On the senses, instincts, and intelligence of animals: with special reference to insects. K. Paul, Trench \& co.

Lynch, J. J. (n.d.). An Interview with James J. Lynch. Part I: Speaking Heart to Heart. Interview by Paul J. Rosch. Retrieved from http://www.stress.org/interviewSpeakingHeartToHeart.htm

Lynch, J. J. (1987). W. Horsley Gantt's effect of person. In F. J. McGuigan \& T. A. Ban (Eds.), Critical Issues in Psychology, Psychiatry, and Physiology: A Memorial to W. Horsley Gantt (pp. 93-106). Amsterdam, Netherlands: Gordon and Beach Publishers.

Lynch, J. J., \& Gantt, H. W. (1968a). Comparison of the CR to the UR in classical heart rate conditioning: The effect of person and its integration with shock. Conditional Reflex, 3, 133.

Lynch, J. J., \& Gantt, H. W. (1968b). The heart rate component of the social reflex in dogs: The conditional effects of petting and person. Conditional Reflex, 3, 6980.

Lynch, J. J., \& McCarthy, J. F. (1967). The effect of petting on a classically conditioned emotional response. Behaviour Research and Therapy, 5(1), 55-62. doi:10.1016/0005$\underline{\text { 7967(67)90056-3 }}$ 
Lynch, J. J., \& McCarthy, J. F. (1969). Social responding in dogs: Heart rate changes to a person. Psychophysiology, 5(4), 389-393. doi:10.1111/j.1469-8986.1969.tb02838.x

Maier, S. F. (2001). Exposure to the stressor environment prevents the temporal dissipation of behavioral depression/ learned helplessness. Biological Psychiatry, 49, 763-773. doi:10.1016/S0006-3223(00)01095-7

Maier, S. F., Seligman, M. E. P, \& Solomon, R. L. (1969). Pavlovian fear conditioning an learned helplessness: Effects on escape and avoidance behavior of (a) the CSUS contingency and (b) the independence of the US and voluntary responding. In B. A. Campbell \& R. M. Church (Eds.) Punishment and Aversive Behavior (pp. 299-342). New York, NY: Appleton-Century-Crofts.

McBryde, W. C., \& Murphree, O. D. (1974). The rehabilitation of genetically nervous dogs. Pavlovian Journal of Biological Science, 9(2), 76-84.

McIntire, R. W. (1965). The training of dogs for field reconnaissance. (Report No. 0724674). Retrieved from http://www.stormingmedia.us/

McIntire, R. W. (1967). The relative effectiveness of stressful and rewarding characteristics of primary and social reinforcers in the control of canine behavior. (Accession number AD0832920). Retrieved from http:// www.dtic.mil/dtic/

McIntire, R. W. (1968). Dog training, reinforcement, and behavior in unrestricted environments. American Psychologist, 23(11), 830-831. doi:10.1037/h0037742

McIntire, R., \& Colley, T. A. (1967). Social reinforcement in the dog. Psychological Reports, 20 (3 pt. 1), 843-846.

Melzack, R. (1954). The genesis of emotional behavior: An experimental study of the dog. Journal of Comparative and Physiological Psychology, 47(2), 166-168. doi:10.1037/ $\underline{\mathrm{h} 0055840}$

Melzack, R. (1972). Effects of early perceptual restriction on simple visual discrimination. Science, 137, 978-979. doi:10.1126/science.137.3534.978

Melzack, R., \& Burns, S. K. (1965). Neurophysiological effects of earlysensoryrestriction. ExperimentalNeurology, 13, 163-175. doi:10.1016/0014-4886(65)90106-8

Melzack, R., \& Scott, T. H. (1957). The effects of early experience on the response to pain. Journal of Comparative and Physiological Psychology, 50(2), 155161. doi: $10.1037 / \mathrm{h} 0047770$

Melzack, R., \& Thompson, W. R. (1956). Effects of early experience on social behaviour. Canadian Journal of Psychology/Revue canadienne de psychologie, 10, 82-90. doi:10.1037/h0083664

Miklósi, Á., Polgárdi, R., Topál, J., \& Csányi, V. (1998). Use of experimenter-given cues in dogs. Animal Cognition, 1 (2), 113-121. doi:10.1007/s100710050016

Morgan, C. (1894). Introduction to Comparative Psychology. London, UK: Walter Scott Ltd. doi:10.1037/11344-000
Murphree, O. D. (1974). Procedure for operant conditioning of the dog. Pavlovian Journal of Biological Science, 9(1), 46-50. doi:10.1111/j.1469-8986.1967.tb02727.x

Murphree, O. D., DeLuca, D. C., \& Angel, C. (1974). Psychopharmacological facilitation of operant conditioning of genetically nervous catahoula and pointer dogs. Pavlovian Journal of Biological Science, 9(1), $17-$ 24.

Murphree, O. D., Dykman, R. A., \& Peters, J. E. (1967a). Genetically-determined abnormal behavior in dogs: Results of behavioral tests. Conditional Reflex, 2(3), 199205.

Murphree, O. D., Dykman, R. A., \& Peters, J. E. (1967b). Operant condition of two strains of the pointer dog. Psychophysiology, 3(4), 414-417.

Murphree, O. D. \& Newton, J. E. O. (1971). Crossbreeding and special handling of genetically nervous dogs. Conditional Reflex, 6(3), 129-136.

Murphree, O. D., Peters, J. E., \& Dykman, R. A. (1967). Effect of person on nervous, stable, and crossbred pointer dogs. Conditional Reflex, 2(4), 273-276.

Murphree, O. D., Peters, J. E., \& Dykman, R. A. (1969). Behavioral and autonomic results from crossing nervous and stable dogs. Conditional Reflex, 3(3), 140.

Newton, J.E. O., \& Chapin, J. L. (1978). Operant performance patterns of normal and nervous water-deprived dogs. Pavlovian Journal of Biological Science, 13(1), 22-28.

Newton, J. E. O., Teitelbaum, H. A., \& Gantt, W. H. (1968). An attempt to condition the cardiac response to person. Conditional Reflex, 3(2), 140-141.

Nonidez, J. F. (1941). Foreword. In C. R. Stockard (Ed.), The Genetic and Endocrinic Basis for Differences in Form and Behavior (viii-x). Philadelphia, PA: Wistar Institute of Anatomy and Biology.

Overmier, B. J. (1996). Richard L. Solomon and learned helplessness. Integrative Physiological and Behavioral Science, 31, 331-337. doi:10.1007/BF02691436

Overmier, J. B., \& Seligman, M. E. P. (1967). Effects of inescapable shock upon subsequent escape and avoidance responding. Journal of Comparative and Physiological Psychology, 63, 28-33. doi:10.1037/h0024166

Pavlov, I. P. (1927). Conditional Reflexes: An Investigation of the Physiological Activity of the Cerebral Cortex. Oxford, England: Oxford University Press.

Pfaffenberger, C. J. (2002). The New Knowledge of Dog Behavior. Wenatchee, WA: Dogwise Publishing. (Original work published 1963)

Pfaffenberger, C. J., \& Scott, J. P. (1959). The relationship between delayed socialization and trainability in guide dogs. Journal of Genetic Psychology, 95, 145-155.

Pfaffenberger, C. J., Scott, J. P., Fuller, J. L., Ginsburg, B. E., \& Bielfelt, S. W. (1976). Guide dogs for the blind: Their selection, development, and training. Amsterdam, 
Netherlands: Elsevier Science Ltd.

Pryor, K. (1999). Don't Shoot the Dog: The New Art of Teaching and Training (Rev. ed.). New York, NY: Bantam Books.

Razran, H. S., \& Warden, C. J. (1929). The sensory capacities of the dog as studied by the conditioned reflex method (Russian schools). Psychological Bulletin, 26(4), 202-222. doi: 10.1037/h0073189

Reese, W. G. (1985). Pavlovian Society Awards. Pavlovian Journal of Biological Science, 20, 155-162.

Reese, W. G., Peters, J. E., \& Dykman, R. A. (1987). Gantt on Gantt. In F. J. McGuigan \& T. A. Ban (Eds.), Critical Issues in Psychology, Psychiatry, and Physiology: A Memorial to W. Horsley Gantt (pp. 17-56). Amsterdam, Netherlands: Gordon and Beach Publishers.

Rescorla, R. A. (1966). Predictability and number of pairings in Pavlovian fear conditioning. Psychonomic Science, 4(11), 383-384.

Rescorla, R. A. (1967a). Inhibition of delay in Pavlovian fear conditioning. Journal of Comparative and Physiological Psychology, 64(1), 114-120. doi:10.1037/h0024810

Rescorla, R. A. (1967b). Pavlovian conditioning and its proper control procedures. Psychological Review, 74, 7180. doi: $10.1037 / \mathrm{h} 0024109$

Rescorla, R. A. (1968). Pavlovian conditioned fear in Sidman avoidance learning. Journal of Comparative and Physiological Psychology, 65(1), 55-60. doi:10.1037/ $\underline{\mathrm{h} 0025412}$

Rescorla, R. A. (1969). Establishment of a positive reinforcer through contrast with shock. Journal of Comparative and Physiological Psychology, 88(2, pt. 1), 260-263. doi:10.1037/h0026789

Rescorla, R. A. (1995). Richard L. Solomon (1918-1995). Biographical Memoirs. Washington, D. C.: National Academies Press. Retrieved from http://www.nap.edu/ html/biomems/rsolomon.html

Rescorla, R. A., \& Solomon, R. L. (1967). Two-process learning theory: Relationships between Pavlovian conditioning and instrumental learning. Psychological Review, 74(3), 151-182. doi:10.1037/h0024475

Romanes, G. (1883). Animal Intelligence. New York: D. Appleton \& Co.

Romanes, G. (1887). Experiments on the Sense of Smell in Dogs. Nature, 36, 273-274. doi:10.1038/036273a0

Ruiz, G., Sánchez, N., \& De la Casa, L. G. (2003). Pavlov in America: A heterodox approach to the study of his influence. Spanish Journal of Psychology, 6, 99-111.

Schlosberg, H. (1934). Conditioned responses in the white rat. The Pedagogical Seminary and Journal of Genetic Psychology, 45, 303-335.

Scott, J. P. (1958). Critical periods in the development of social behavior in puppies. Psychosomatic Medicine, 20, $42-54$.
Scott, J. P. (1978, September 29). [Letter to J. Holstein]. John Paul Scott Collection (Box 36, Folder 4), Joan Staats Library, Jackson Laboratory, Bar Harbor, ME.

Scott, J. P., \& Fuller, J. L. (1965). Genetics and the Social Behavior of the Dog: The Classic Study. Chicago, IL: The University of Chicago Press.

Scott, J. P., \& Marston, M.-V. (1950). Critical periods affecting the development of normal and mal-adjustive social behavior of puppies. The Pedagogical Seminary and Journal of Genetic Psychology, 77, 25-60.

Seligman, M. E., \& Maier, S. F. (1967). Failure to escape traumatic shock. Journal of Experimental Psychology, 74(1), 1-9. doi:10.1037/h0024514

Shapiro, M. M. (1960a). Classical salivary condition in dogs. Dissertation Abstracts, 20, 4188-4189.

Shapiro, M. M. (1960b). Respondent salivary conditioning in dogs during operant lever pressing in dogs. Science, 132, 361-364. doi:10.1126/science.132.3427.619

Shapiro, M. M., \& Herendeen, D. L. (1975). Food-reinforced inhibition of conditioned salivation in dogs. Journal of Comparative and Physiological Psychology, 88(2), 628632. doi:10.1037/h0076432

Shapiro, M. M., Miller, T. M., \& Bresnahan, J. L. (1966). Dummy trials, novel stimuli, and Pavlovian-trained stimuli: Their effect upon instrumental and consummatory response relationships. Journal of Comparative and Physiological Psychology, 61(3), 480-483. doi:10.1037/ $\underline{\mathrm{h} 0023271}$

Shapiro, M. M., Mugg, G. J., \& Ewald, J. (1971). Instrumental preferences and conditioned preparatory responses in dogs. Journal of Comparative and Physiological Psychology, 74(2), 227-232. doi:10.1037/h0030343

Shepard, E. (2001). Finding aid to The Charles Rupert Stockard, PhD (1879-1939) Papers. Retrieved from http:// www.med.cornell.edu/archives/our_collection/personal. $\underline{\mathrm{html}}$

Shepherd, W. T. (1915). Adaptive intelligence in dogs and cats, as compared with adaptive intelligence in rhesus monkeys. American Journal of Psychology, 26, 211-216. doi: $10.2307 / 1413250$

Shepherd, W. T. (1919) On sound discrimination in dogs. The American Journal of Psychology, 30, 291-294. doi: $10.2307 / 1413878$

Sidman, M. (1954). The temporal distribution of avoidance responses. Journal of Comparative Physiological Psychology, 47(5), 399-402. doi:10.1037/h0059155

Sinn, D. L., Gosling, S. D., \& Hilliard, S. (2010). Personality and performance in military working dogs: Reliability and validity of behavioral tests. Applied Animal Behaviour Sciences, 127,51-65.doi:10.1016/j.applanim.2010.08.007

Solomon, R. L., Kamin, L. J., \& Wynne. L. C. (1953). Traumatic avoidance learning: the outcomes of several extinction procedures with dogs. Journal of Abnormal and 
Social Psychology, 49, 291-302. doi:10.1037/h0058943

Solomon, R. L. \& Wynne. L. C. (1953). Traumatic avoidance learning: acquisition in normal dogs. Psychological Monographs, 67(4), 19.

Solomon, R. L., \& Wynne. L. C. (1954). Traumatic avoidance learning: the principles of anxiety conservation and partial irreversibility. Psychological Review, 61(6), 353-385. doi: $\underline{10.1037 / \mathrm{h} 0054540}$

Solomon, R. L., \& Wynne. L. C. (1955). Traumatic avoidance learning: acquisition and extinction in dogs deprived of normal peripheral autonomic function. Genetic Psychology Monographs, 52, 241-284.

Spady, T. C., \& Ostrander, E. A. (2008). Canine behavioral genetics: Pointing out the phenotypes and herding up the genes. American Journal of Human Genetics, 82(1), 1018. doi:10.1016/j.ajhg.2007.12.001

Staff. (1950). Manual of dog testing techniques. Bar harbor, ME: Roscoe B. Jackson Memorial Laboratory.

Stanley, W. C. (1966). The passive person as reinforcer in isolated beagle puppies. Psychonomic Science, 2, 21-22.

Stanley, W. C., Morris, D. D, \& Trattner, A. (1965). Conditioning with a passive person reinforcer and extinction in Shetland sheep dog puppies. Psychonomic Science, 2, 19-20.

Stockard, C. R. (Ed.) (1941). The Genetic and Endocrinic Basis for Differences in Form and Behavior. Philadelphia, PA: Wistar Institute of Anatomy and Biology.

Svartberg, K., \& Forkman, B. (2002). Personality traits in the domestic dog (Canis familiaris). Applied Animal Behaviour Science, 79(2), 133-156. doi:10.1016/S01681591(02)00121-1

Thomas, K. J., Murphree, O. D., \& Newton, J. E. (1972). Effect of person and environment on heart rates in two strains of pointer dogs. Conditional Reflex, 7, 74-81. doi: $10.1007 / \mathrm{BF} 03000477$

Thompson, W. R., \& Heron, W. (1954a). The effects of early restriction on activity in dogs. Journal of Comparative Physiological Psychology, 47(1), 77-82. doi:10.1037/ h0055664

Thompson, W. R., \& Heron, W. (1954b). The effects of restricting early experience on the problem-solving capacity of dogs. Canadian Journal of Psychology, 8(1), 17-31. doi:10.1037/h0083595

Thompson, W. R., Melzack, R., \& Scott, T. H. (1956). 'Whirling behavior' in dogs as related to early experience. Science, 123, 939. doi:10.1126/science.123.3204.939

Thorndike, E. (1898). Animal Intelligence: An Experimental Study of the Associative Processes in Animals. New York, NY: Columbia University Press. doi:10.1037/10780-000

Thorndike, E. (1899). Do animals reason? Popular Science Monthly, LV, 480-490.

Todes, D. P. (2000). Ivan Pavlov: Exploring the Animal Machine. New York, NY: Oxford University Press.
Todes, D. P. (2001). Pavlov's Physiology Factory: Experiment, Interpretation, Laboratory Enterprise. Baltimore, MD: The Johns Hopkins University Press.

Topál, J., Miklósi, Á., \& Csányi, V. (1997). Doghuman relationship affects problem-solving behavior in the dog. Anthrozoös, 10(4), 214-224. doi: $10.2752 / 089279397787000987$

Townshend, E. (2009). Darwin's Dogs: How Darwin's Pets Helped Form a World-Changing Theory of Evolution. Frances Lincoln.

Tryon, R. C. (1940). Genetic differences in maze learning ability in rats. Yearbook of the National Society for the Study of Education, 39(I), 111-119.

Watson, J. B. (1916). The place of the conditioned-reflex in psychology. The Psychological Review, 23, 89-116. doi: $10.1037 / \mathrm{h} 0070003$

Weiss, E., \& Greenberg, G. (1997). Service dog selection tests: Effectiveness for dogs from animal shelters. Applied Animal Behaviour Science, 53(4), 297-308. doi:10.1016/ $\underline{\mathrm{S} 0168-1591(96) 01176-8}$

West, M. J., \& King, A. P. (1987). Settling nature and nurture into an ontogenetic niche. Developmental Psychobiology, 20, 549-562. doi:10.1002/dev.420200508

Wynne, C. D. L. (2007). What are animals? Why is anthropomorphism still not a scientific approach to behavior? Comparative Cognition \& Behavior Reviews, 2, 125-135. doi:10.3819/ccbr.2008.20008 